\title{
Anopheles gambiae larvae mount stronger immune responses against bacterial infection than adults: evidence of adaptive decoupling in mosquitoes
}

\author{
Garrett P. League, Tania Y. Estévez-Lao, Yan Yan, Valeria A. Garcia-Lopez and Julián F. Hillyer
}

\begin{abstract}
Background: The immune system of adult mosquitoes has received significant attention because of the ability of females to vector disease-causing pathogens while ingesting blood meals. However, few studies have focused on the immune system of larvae, which, we hypothesize, is highly robust due to the high density and diversity of microorganisms that larvae encounter in their aquatic environments and the strong selection pressures at work in the larval stage to ensure survival to reproductive maturity. Here, we surveyed a broad range of cellular and humoral immune parameters in larvae of the malaria mosquito, Anopheles gambiae, and compared their potency to that of newly-emerged adults and older adults.
\end{abstract}

Results: We found that larvae kill bacteria in their hemocoel with equal or greater efficiency compared to newly-emerged adults, and that antibacterial ability declines further with adult age, indicative of senescence. This phenotype correlates with more circulating hemocytes and a differing spatial arrangement of sessile hemocytes in larvae relative to adults, as well as with the individual hemocytes of adults carrying a greater phagocytic burden. The hemolymph of larvae also possesses markedly stronger antibacterial lytic and melanization activity than the hemolymph of adults. Finally, infection induces a stronger transcriptional upregulation of immunity genes in larvae than in adults, including differences in the immunity genes that are regulated.

Conclusions: These results demonstrate that immunity is strongest in larvae and declines after metamorphosis and with adult age, and suggest that adaptive decoupling, or the independent evolution of larval and adult traits made possible by metamorphosis, has occurred in the mosquito lineage.

Keywords: Diptera, Hemocyte, Phagocytosis, Melanization, Phenoloxidase, Antimicrobial peptide, Hemolymph, Metamorphosis

\section{Background}

Mosquitoes face the threat of infection during all stages of their holometabolous life cycle. These threats arise from numerous sources, including the microbe-rich aquatic environments where larvae reside and the infected blood meals that adults ingest. To combat pathogens that invade their hemocoel (body cavity), mosquitoes have evolved a diverse array of cellular and humoral immune responses [1]. These responses begin when pathogenassociated molecular patterns are recognized by host-

\footnotetext{
*Correspondence: julian.hillyer@vanderbilt.edu

Department of Biological Sciences, Vanderbilt University, Nashville, TN, USA
}

derived pattern recognition receptors. This recognition triggers the amplification or repression of extracellular signaling cascades, the initiation of intracellular signal transduction pathways and, ultimately, the activation or expression of immune effectors. These immune effectors, together with the circulating and sessile hemocytes (insect blood cells) that produce many of them, kill pathogens via phagocytosis, lysis, melanization, and other mechanisms $[2,3]$.

Despite the critical importance of immune responses for survival, the vast majority of what we know about the mosquito immune system comes exclusively from 
experiments conducted on adult females, as this stage and sex is responsible for the transmission of bloodborne pathogens such as those that cause dengue [4-6], lymphatic filariasis $[7,8]$, and malaria $[9,10]$. Recently, we described the functional integration of the circulatory and immune systems of mosquito larvae, whereby pathogens are phagocytosed and melanized by tracheal tuft hemocytes that surround the sole entry point of hemolymph (insect blood) into the heart [11]. However, few other studies have described immune responses in larvae. Most of these studies have focused on uninfected larvae by assaying the developmental expression of immunity genes [12-25] or by describing hemocyte subpopulations [26, 27]. Few studies describe immune response in larvae assessed immune gene expression or protein levels in infected larvae [28-32], and prior to our recently published work [11], to our knowledge only one study had described a larval immune response: the encapsulation of the aquatic fungus, Lagenidium giganteum, by Aedes aegypti [33].

Although the immune system of mosquito larvae remains largely unexplored, two general lines of reasoning led us to hypothesize that larvae have evolved more proficient means of neutralizing infections than adults. First, by virtue of inhabiting aquatic environments that are rife with microorganisms, mosquito larvae are under constant threat of infection, whereas adults are less likely to encounter pathogens in their terrestrial and aerial habitats. Secondly, larvae have yet to fulfill any of their reproductive potential, and hence, strong selection pressures must be at work on the larval immune system to increase the probability of their survival to reproductive maturity [34-36]. As a corollary to this, as mosquito adults age and fulfill their reproductive potential, investment in the immune system is expected to wane in order to reallocate resources to other adult processes, such as reproduction [37-39]. If larval and adult immune responses indeed differ in either strength or composition, this would imply that future studies could no longer assume complete continuity in immune responses across life stages, and that metamorphosis has, to some extent, decoupled the larval and adult immune systems, thus enabling their independent evolution [40, 41]. Furthermore, if immune responses differ across life stages, this would have important implications for the creation of stage-specific control measures that are better tailored to the specific immune responses of each life stage.

To test the hypothesis that larvae display stronger immune responses compared to adults, and to gain a better mechanistic understanding of the larval response to infection, we conducted a series of comparative analyses of immune responses in larval and adult Anopheles gambiae. We show that mosquito larvae are more proficient than adults in killing bacteria, and that this correlates with stronger cellular and humoral immune responses in larvae compared to adults. Furthermore, we uncovered evidence of immune senescence within the adult stage, as the antimicrobial immune response in the hemocoel of adults declines over the first five days of adulthood.

\section{Methods}

\section{Mosquito rearing and maintenance}

Anopheles gambiae Giles (sensu stricto; G3 strain) were reared and maintained at $27{ }^{\circ} \mathrm{C}$ and $75 \%$ relative humidity in an environmental chamber set to a $12: 12 \mathrm{~h}$ light:dark cycle. Larvae were reared in plastic tubs containing deionized water and fed a combination of koi food and baker's yeast. The resulting pupae were separated from the larvae and placed into plastic containers with marquisette tops, and adults that emerged were fed a $10 \%$ sucrose solution. All experiments were performed on fourth-instar larvae and adult female mosquitoes at 1 and 5 days post-emergence.

\section{Mosquito injection and bacterial infection}

Mosquito larvae were immobilized by removal of excess water and injected at the mesothorax [42]. Mosquito adults were cold anesthetized and injected at the thoracic anepisternal cleft. For all experiments involving bacterial injection, a Nanoject II Auto-Nanoliter Injector (Drummond Scientific Company, Broomall, PA, USA) was used to inject $69 \mathrm{nl}$ of the following: live, tetracycline resistant, GFP-expressing E. coli (modified DH $5 \alpha$; GFP-E. coli) in Luria-Bertani's rich nutrient medium (LB), heat-killed GFP-E. coli, heat-killed Micrococcus luteus, heat-killed Enterobacter sp. isolate Ag1 [43, 44], or LB medium alone. For all experiments involving cellular staining solutions (see below), approximately $0.2 \mu \mathrm{l}$ of a solution was injected using an aspirator.

Bacteria were grown overnight in a $37{ }^{\circ} \mathrm{C}$ (or $27^{\circ} \mathrm{C}$ for Enterobacter) shaking incubator until they reached an optical density of approximately $\mathrm{OD}_{600}=5$, as measured in a BioPhotometer plus spectrophotometer (Eppendorf AG, Hamburg, Germany). For experiments using live GFP-E. coli, live bacteria were injected at either $\mathrm{OD}_{600}=5$, which we refer to as the high dose, or diluted with $\mathrm{LB}$ medium to $\mathrm{OD}_{600}=1$, which we refer to as the low dose. Unless otherwise stated, all experiments were carried out at the high dose. The absolute doses of the bacterial inoculums were determined by performing serial dilutions of the GFP-E. coli cultures and spreading them on LB agar plates. These plates were grown overnight at $37^{\circ} \mathrm{C}$, the number of resulting colony forming units (CFUs) were counted, and the doses were calculated. Low doses of $E$. coli $\left(\mathrm{OD}_{600}=1\right)$ ranged from 1932 to 33,741 (average $=18,061$ ) and high doses $\left(\mathrm{OD}_{600}=5\right)$ ranged from 53,889 to 77,970 
(average $=65,171)$. These high intensity doses were selected because the pathogenicity associated with an $E$. coli infection is low relative to infection with other bacteria [45]. For experiments using heat-killed bacteria, $50 \mu \mathrm{l}$ of bacterial culture was incubated at $95{ }^{\circ} \mathrm{C}$ for $10 \mathrm{~min}$ on an IncuBlock heating block (Denville Scientific, Holliston, MA, USA), and injected after cooling. Plating of the heat-killed cultures, which resulted in no CFUs, confirmed that all bacteria were dead.

\section{Measurement of in vivo bacteria killing efficiency}

Mosquito larvae, 1-day-old adults and 5-day-old adults were injected with either low or high doses of GFP-E. coli. After $24 \mathrm{~h}$, mosquitoes were homogenized in phosphate buffered saline (PBS; $\mathrm{pH} 7.0$ ) and a dilution was spread on LB agar plates containing tetracycline. After overnight incubation at $37{ }^{\circ} \mathrm{C}$, the resulting CFUs in each plate were screened for GFP fluorescence, and were counted to calculate infection intensities. Four independent trials, each paired for both mosquito age (including stage) and E. coli dose, were conducted. Each trial consisted of approximately 10 mosquitoes per group, and the data were combined and analyzed using the Kruskal-Wallis test, followed by Dunn's multiple comparisons post-hoc test.

\section{Quantification of circulating hemocytes}

For each mosquito, an incision was made across the lateral and ventral portions of the suture that joins the 7 th and 8th abdominal segment of naïve, injured (LBinjected), and E. coli-infected larvae, 1-day-old adults and 5-day-old adults at $24 \mathrm{~h}$ post-treatment. A finely pulled glass capillary needle was then inserted into the thorax, approximately $200 \mu \mathrm{l}$ of Schneider's Drosophila medium was perfused through the mosquito, and the diluted hemolymph was collected within two $1 \mathrm{~cm}$ diameter etched rings on a Rite-On glass slide (Gold Seal; Portsmouth, NH, USA) [46]. After allowing the hemocytes to adhere to the slide for $20 \mathrm{~min}$, cells were fixed and stained using Hema 3 (Fisher Scientific, Pittsburgh, PA, USA), and, after drying, mounted with coverslips using Poly-Mount (Polysciences, Warrington, PA, USA) $[45,47]$. The total number of hemocytes was then counted under bright-field conditions at $40 \times$ magnification using either a Nikon 90i compound microscope (Nikon, Tokyo, Japan) or an Olympus BH-2 microscope (Olympus, Tokyo, Japan). Three independent trials consisting of approximately 5 individuals per treatment group were conducted ( $n=14-16$ per group). Data were analyzed by two-way ANOVA, using age (including stage) and treatment as variables, followed by Šidák's post-hoc test.

\section{Quantification of sessile hemocytes associated with the} dorsal abdomen

The hemocytes from naïve, injured, and E. coli-challenged larvae, 1-day-old adults and 5-day-old adults were fluorescently labelled in vivo at $24 \mathrm{~h}$ posttreatment by injecting live animals with $67 \mu \mathrm{M}$ of Vybrant CM-DiI Cell-Labeling Solution (Invitrogen, Carlsbad, CA, USA) and $1.08 \mathrm{mM}$ Hoechst 33342 nuclear stain (350/461; Invitrogen) in PBS, and incubating them at $27{ }^{\circ} \mathrm{C}$ and $75 \%$ relative humidity for $20 \mathrm{~min}$ $[11,48]$. Larvae were fixed for $5-10 \mathrm{~min}$ by immersion in $4 \%$ paraformaldehyde (Electron Microscopy Sciences, Hatfield, PA, USA) and then dissected along a coronal plane. Specimens were rinsed in PBS, and the dorsal abdomens, without the internal organs, were mounted on a glass slide using Aqua-Poly/Mount (Polysciences Inc., Warrington, PA, USA). Adults were fixed for 5-10 min by injection of $4 \%$ paraformaldehyde and then dissected along a coronal plane. Specimens were placed in $0.5 \%$ Tween in PBS, rinsed briefly in PBS, and the dorsal abdomens, without the internal organs, were mounted on a glass slide using Aqua-Poly/Mount.

Dissected larval and adult dorsal abdomens were imaged under bright-field and fluorescence illumination using a Nikon 90i microscope connected to a Nikon Digital Sight DS-Qi1 Mc monochrome digital camera and Nikon's Advanced Research NIS Elements software. To render images with extended focal depth, Z-stacks of specimens were acquired using a linear encoded Zmotor, and all images within a stack were combined to form a single focused image using either NIS Elements' Maximum Intensity Projection (for quantification) or Extended Depth of Focus (EDF; for viewing) modules.

Sessile hemocytes attached to the dorsal abdominal wall were quantified by two methods. First, custom polygonal regions of interest (ROI) were drawn on the maximum intensity projections to delineate the dorsal and lateral portions of abdominal segments $2-8$, as was done previously for the periostial regions and tracheal tufts of larvae [11], and the mean pixel intensities of CM-Dil fluorescence within the ROIs were measured and recorded for each abdominal segment as well as for the entire dorsal and lateral abdomen (Additional file 1: Figure S1). For each specimen, background fluorescence was removed by subtracting the intensity values from the abdominal segments of each group's corresponding unstained naïve specimens. Secondly, EDF images were used to manually count the sessile hemocytes within abdominal segments 4, 5 and 6, with these hemocytes categorized as being bound to one of three tissues: (i) the cuticular integument, (ii) the heart (periostial hemocytes), or (iii) the trachea. Data were analyzed by two-way ANOVA, using age (including stage) and treatment as variables, followed by Šidák's post-hoc test. 


\section{Quantification of phagocytosis by circulating hemocytes} Larvae, 1-day-old adults and 5-day-old adults were injected with $E$. coli, and $1 \mathrm{~h}$ later, hemocytes were perfused as described above, except that each mosquito was perfused with approximately $50 \mu \mathrm{l}$ of Schneider's medium and all the perfusate was collected onto a single etched ring. After allowing the hemocytes to adhere to the slide for $20 \mathrm{~min}$, cells were fixed for $5 \mathrm{~min}$ by adding $50 \mu \mathrm{l}$ of PBS containing 4\% formaldehyde and $0.03 \mathrm{mM}$ Hoechst 33342 nuclear stain. After removal of the fixation and staining solution, slides were mounted with coverslips using Aqua-Poly/Mount. Specimens were then examined under $100 \times$ magnification using simultaneous DIC and fluorescence illumination on a Nikon 90i microscope. For each mosquito, the number of bacteria that had been phagocytosed by each of the first 100 hemocytes viewed was counted. These values were used to calculate two parameters: (i) the phagocytic index, which is defined as the percentage of cells that engage in phagocytosis; and (ii) the phagocytic capacity, which is defined as the average number of phagocytosed bacteria per hemocyte [45]. Three independent trials consisting of 10 individuals per age were conducted. Data were analyzed by the Kruskal-Wallis test, followed by Dunn's post-hoc test.

\section{Quantification of antimicrobial hemolymph activity}

Using a hemolymph extraction method we adapted from a protocol used for Drosophila larvae and adults [49], hemolymph was extracted at $24 \mathrm{~h}$ after treatment from larvae, 1-day-old adults and 5-day-old adults that were naive, injured, or treated with heat-killed E. coli, $M$. luteus or Enterobacter sp. Briefly, an incision approximately $5 \mathrm{~mm}$ in length was made into the bottom of a $0.6 \mathrm{ml}$ microfuge tube using a feather blade, and freshly wounded larvae or adults were placed inside. This tube was then inserted into a $1.5 \mathrm{ml}$ microfuge tube, which was centrifuged to collect the hemolymph. For each larval collection, up to ten individuals were placed on a Kimwipe to remove all external water before placing the larvae on the inner rim of the $0.6 \mathrm{ml}$ tube. An insect pin was used to puncture the thorax of each larva and the tubes were centrifuged for $10 \mathrm{~s}$ in a mini centrifuge. This resulted in the collection of $1-2 \mu \mathrm{l}$ of hemolymph. For each adult collection, 20-30 individuals were coldanesthetized and an insect pin was used to puncture the lateral thorax. The mosquitoes were then placed in the $0.6 \mathrm{ml}$ tube and centrifuged at $2152 \mathrm{rcf}$ for $5 \mathrm{~min}$ at $4{ }^{\circ} \mathrm{C}$. This resulted in the collection of $1-2 \mu$ l of hemolymph. Immediately after collection, hemolymph was stored in a $20{ }^{\circ} \mathrm{C}$ freezer until use.

Antimicrobial activity of hemolymph was measured via a zone of inhibition assay that we adapted from protocols developed for bumblebee workers [50] and mealworm beetle larvae [51]. Briefly, a $2 \mathrm{ml} M$. luteus culture was grown overnight in LB broth at $37{ }^{\circ} \mathrm{C}$ in a shaking incubator until it reached approximately $\mathrm{OD}_{600}=10$. The entire $M$. luteus culture was then added to $20 \mathrm{ml}$ of sterile, liquid $1 \%$ LB agar that was maintained at $55^{\circ} \mathrm{C}$ by immersion in a water bath. The solution was mixed, and $5 \mathrm{ml}$ of the $M$. luteus-LB agar solution was poured into $9 \mathrm{~cm}$ diameter Petri dish plates. After solidifying, equidistant holes were created in the agar $1.5 \mathrm{~cm}$ from the outer edge of the Petri dish by piercing and suctioning using a $1 \mathrm{~mm}$ tip sterile glass Pasteur pipette. Each hole was then loaded with $1 \mu \mathrm{l}$ of hemolymph and, once the hemolymph had been absorbed by the agar, the plates were placed upside down in a $37^{\circ} \mathrm{C}$ incubator for $16 \mathrm{~h}$. Plates were then scanned at 1200 pixels per inch using an Epson Perfection V600 scanner (Epson America, Inc., Long Beach, CA), and images were analyzed using ImageJ software [52]. For each sample, the diameters of the individual zones of bacterial growth inhibition were measured three times at different locations, and the average of these diameters was used to calculate the areas of the zones of inhibition. Five independent trials for each of the three bacterial treatments were conducted, each consisting of 2-3 larval and 1-2 adult pooled hemolymph samples per treatment group (naïve, injured, and treated with heat-killed bacteria; $n=12-15$ and $n=5-6$ for larval and adult groups, respectively). The data were combined and analyzed by two-way ANOVA, using age (including stage) and treatment as variables, followed by Šidák's post-hoc test. These experiments were only conducted using plates seeded with $M$. luteus because, as we and others have found, the replication rate of $E$. coli in this in vitro assay outpaces the antimicrobial activity of hemolymph, thus precluding the measurement of zones of inhibition [51].

\section{Quantification of the phenoloxidase activity of hemolymph}

Using the method described for the zone of inhibition assay, hemolymph was extracted from naïve, injured, and $E$. coli-infected larvae, 1-day-old adults and 5-dayold adults at $24 \mathrm{~h}$ post-treatment. Because we noted that using PBS as a solvent causes auto-oxidation of DOPA, and hence darkening that is not caused by phenoloxidase activity, all experiments utilized sterile water as the diluent, and not PBS. After adding $1 \mu \mathrm{l}$ of extracted hemolymph to $50 \mu \mathrm{l}$ of water, $10 \mu \mathrm{l}$ of the diluted hemolymph solution (or water alone in the case of the negative control) was added to a cuvette containing $90 \mu \mathrm{l}$ of one of the following three solutions: (i) $4 \mathrm{mg} / \mathrm{ml} \mathrm{3,4-Di-}$ hydroxy-L-phenylalanine (L-Dopa; Sigma, St. Louis, MO, USA); (ii) $20 \mathrm{mg} / \mathrm{ml}$ Sodium Diethyldithiocarbamate Trihydrate (DETC; Fisher Scientific, Pittsburgh, PA, USA) and $4 \mathrm{mg} / \mathrm{ml} \mathrm{L-DOPA}$; or (iii) water alone. Absorbance readings were measured at $490 \mathrm{~nm}$ every $5 \mathrm{~min}$ for 
30 min using a BioPhotometer plus spectrophotometer. Five independent trials were conducted, each consisting of 1 larval or adult sample per treatment group. The data were combined and analyzed by repeated measures twoway ANOVA, using age (including stage) and treatment as variables, followed by Šidák's post-hoc test.

\section{Quantification of immunity gene expression by qPCR}

Total RNA was extracted from the whole body of approximately forty larvae, twenty 1-day-old adults and twenty 5-day-old adults that were naïve, or had been injected $24 \mathrm{~h}$ earlier with LB (injury), or GFP-E. coli. RNA was purified after homogenization in TRIzol reagent (Invitrogen, Carlsbad, CA), and repurified using the PureLink Micro-to-Midi Total RNA Purification System (Invitrogen). For each sample, $5 \mu \mathrm{g}$ of RNA was treated with RQ1 RNase-Free DNAse I (Promega, Madison, WI, USA) to remove any contaminating genomic DNA, and then used as template for cDNA synthesis using an Oligo $(\mathrm{dT})_{20}$ primer and the SuperScript III First-Strand Synthesis System for RT-PCR (Invitrogen). Real-time quantitative PCR was performed using Power SYBR Green PCR Master Mix (Applied Biosystems, Foster City, CA) on a Bio Rad CFX Connect Real-Time PCR Detection System (Hercules, CA, USA). Relative quantification of mRNA levels was performed using the $2_{\mathrm{T}}^{-\Delta \Delta \mathrm{C}}$ method [53], and mRNA levels were calculated relative to the naïve groups of each mosquito age. In all experiments, ribosomal protein gene RPS7 (AGAP010592) was used as the reference gene, and the ribosomal protein gene RPS17 (AGAP004887) was used as a control. Primer sequences are listed in Additional file 2: Table S1. Melting curve analyses after RT-PCR confirmed that the cDNAs used in the experiments were free of genomic DNA contamination and that only the gene of interest was amplified. Three independent trials were conducted, and each trial was analyzed in duplicate. Data are presented as the average fold-change relative to the naive group of a given life stage or adult age. Data for each gene were analyzed separately by age (stage) using the Kruskal-Wallis test, followed by Dunn's post-hoc test.

\section{Results}

Larvae and newly-emerged adult mosquitoes kill bacteria in their hemocoels more efficiently than older adult mosquitoes

To begin to test whether larval and adult mosquitoes have different immune proficiencies, we infected larvae and differently aged adults with either low $\left(\mathrm{OD}_{600}=1\right)$ or high $\left(\mathrm{OD}_{600}=5\right)$ doses of $E$. coli, and measured their bacterial load $24 \mathrm{~h}$ later. Infections were conducted by means of intrahemocoelic injection to ensure that all animals received the same pathogen dose and to establish a precise time of infection. The $24 \mathrm{~h}$ time-point for sample collection was selected because it gave the mosquito ample time to combat the infection and allowed for the reading of larval immune parameters prior to pupation. It also allows for comparative analyses with other published works because $24 \mathrm{~h}$ is a commonly selected time-point. We found that, for both doses, bacterial killing proficiency differed significantly between the larval and adult stages (Fig. $1 ; \mathrm{OD}_{600}=1$, KruskalWallis: $H=62.85, d f=2, P<0.0001 ; \mathrm{OD}_{600}=5$, Kruskal-Wallis: $H=44.08, d f=2, P<0.0001)$. Specifically, at $24 \mathrm{~h}$ following a low dose infection, the bacterial load in fourth-instar larvae, 1-day-old (newly-emerged) adults and 5 -day-old adults had decreased by $94 \%, 86 \%$ and $22 \%$, respectively. At $24 \mathrm{~h}$ following a high dose infection, bacterial load had decreased by 85 and $81 \%$ in fourth-instar larvae and newly-emerged adults, respectively, but increased by $81 \%$ in older adults. Statistical analysis of the data revealed that larvae killed significantly more bacteria than 1-day-old and 5-day-old adults following the low dose infection (Dunn's test: $P=0.0179$ and $P<0.0001$, respectively), but when infected with the high dose, larvae were only more proficient at killing bacteria than 5-day-old adults (Dunn's test: $P<0.0001$ ). Taken together, these experiments show that larvae and 1-day-old adults display a stronger ability to combat

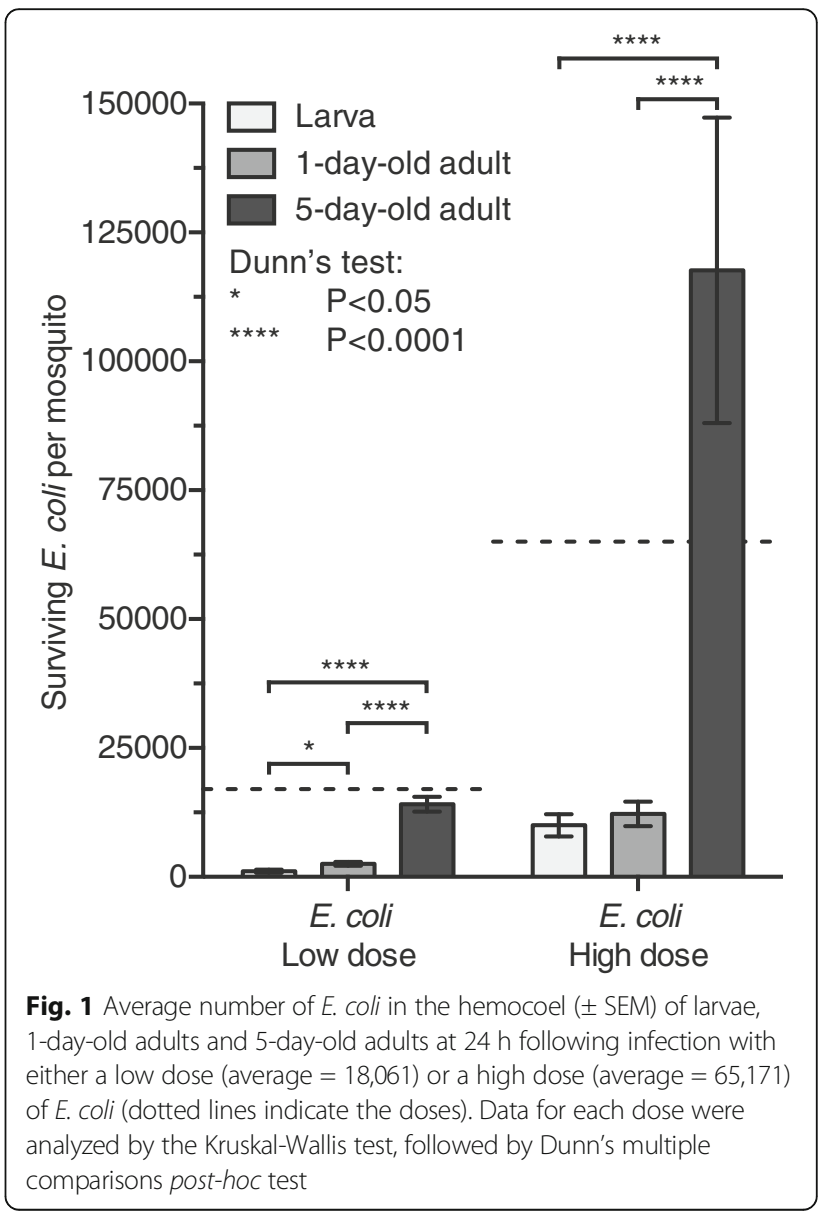


systemic hemocoel infections than 5-day-old adults, and that the difference of the response is more pronounced at higher infection intensities.

\section{Larvae contain more circulating hemocytes than both newly-emerged and older adults, and larval hemocytes increase in abundance following infection}

Because hemocytes are the first cellular responders to infection and kill pathogens via phagocytosis and the production of humoral immune factors [3, 54], we hypothesized that the developmental differences we observed in the killing of $E$. coli could be due to differences in the number of circulating hemocytes available to quell the infection. To test this, we counted the circulating hemocytes in naïve, injured (injected with sterile LB broth), and $E$. coli-infected larvae, 1-day-old adults and 5-dayold adults at $24 \mathrm{~h}$ after treatment.

The number of circulating hemocytes changed significantly with mosquito life stage and age (Fig. 2; two-way ANOVA: $\left.F_{(2,126)}=51.73, P<0.0001\right)$. Specifically, naive larvae contain more circulating hemocytes (2553) than either 1-day-old adults (1561) or 5-day-old adults (1097), and a similar age-related pattern was observed for both injured and infected mosquitoes (Šidák's multiple comparisons post-hoc test: $P \leq 0.0061$ for all comparisons). Treatment also had a significant effect in the number of circulating hemocytes (two-way ANOVA: $F_{(2,126)}=5.469$, $P=0.0053)$, and this was due to an infection-induced increase in the number of circulating hemocytes in infected larvae compared to naïve larvae (Šidák's: $P=0.0327$ ), which is an effect that was not seen in either 1-day-old adults or 5-day-old adults (Šidák's: $P=0.2492$ and $P=0.4774$, respectively). Together, these data show that the number of circulating hemocytes declines following the larva to adult transition, and that this number continues to decline as mosquitoes age.
The spatial arrangement of sessile hemocytes differs between larvae and differently aged adults, and sessile hemocytes increase after infection in newly-emerged adults

We have previously shown that, regardless of the age of an adult mosquito, $75 \%$ of hemocytes circulate with the hemolymph whereas $25 \%$ are sessile, or attached to tissues [46]. Furthermore, the majority of sessile hemocytes are present on the dorsal abdominal wall or the tissues associated with it [46]. Thus, to compare the sessile hemocyte populations of larvae and adults, we labeled hemocytes in vivo using CM-DiI and quantified fluorescence intensity in the dorsal abdomen (Additional file 1: Figure S1).

Spatially, sessile hemocytes in larvae and 1-day-old adults are arranged in segmental bands that encircle each abdominal segment, but hemocytes do not retain this clear segmental pattern in 5-day-old adults due to fewer hemocytes present on the dorsal tergum (Fig. 3a-f). Furthermore, hemocytes in larvae are distinctly aggregated at the 8th segment tracheal tufts that surround the posterior opening of the heart (Fig. 3a), a phenotype not observed in adults. Instead, in adults, hemocytes are aggregated in the periostial regions of the heart (Fig. 3b-f), although this phenotype is less distinct in 1-day-old adults due to more surrounding hemocytes on the dorsal cuticle. Measurements of CM-DiI fluorescence intensity in the dorsal (tergum) and lateral (pleuron) surfaces of the abdomen did not detect differences in the abundance of sessile hemocytes between naïve and injured larvae, 1-day-old and 5-day-old adults (Fig. 3g). However, E. coli infection caused a significant increase in hemocyte intensity in 1-day-old adults relative to both injured 1-dayold adults and infected 5-day-old adults (Fig. 3g; Šidák's: $P=0.0311$ and $P=0.0220$, respectively). When hemocyte intensity was analyzed for each abdominal segment (instead of the entire abdomen), we found that the infection-

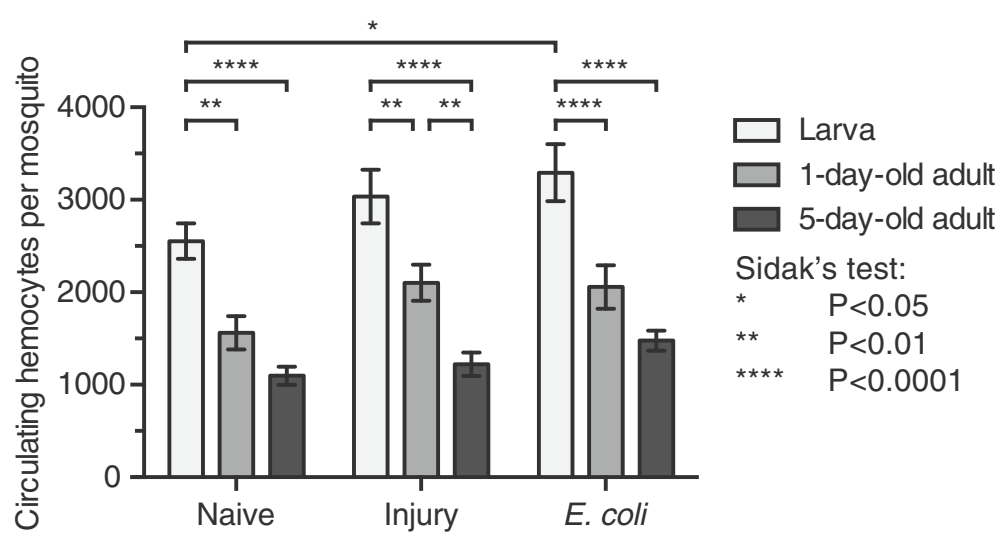

Fig. 2 Average number of circulating hemocytes ( \pm SEM) in naïve, injured, or E. coli-infected (high dose) larvae, 1-day-old adults, and 5-day-old adults at $24 \mathrm{~h}$ post-treatment. Data were analyzed by two-way ANOVA, followed by Šidák's multiple comparisons post-hoc test 

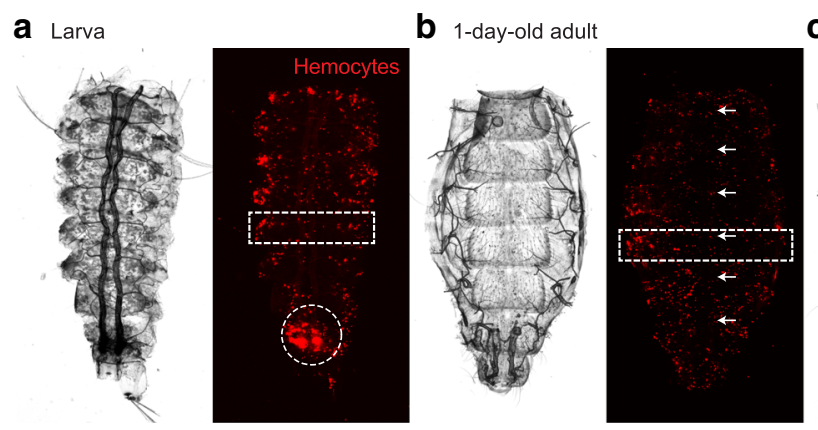

C 5-day-old adult

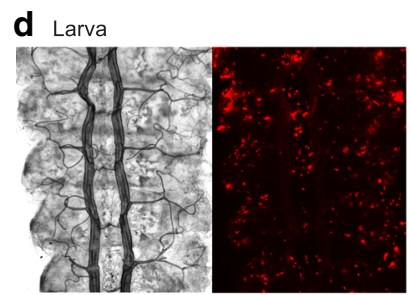

g Whole body

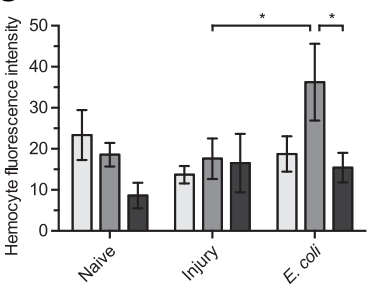

j Abdominal segment 6

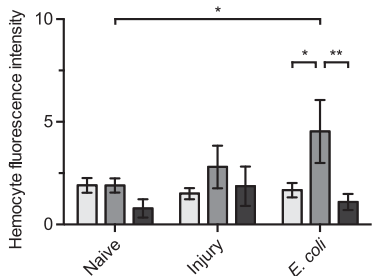

e 1-day-old adult

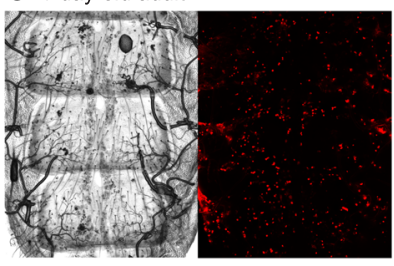

h Abdominal segment 4

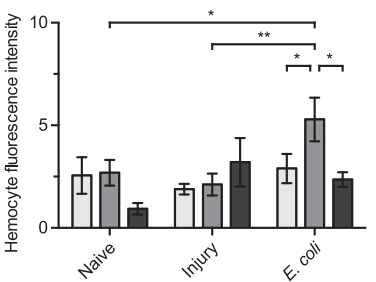

K Abdominal segment 8

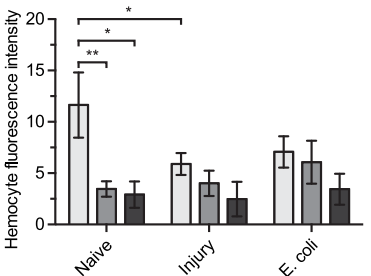

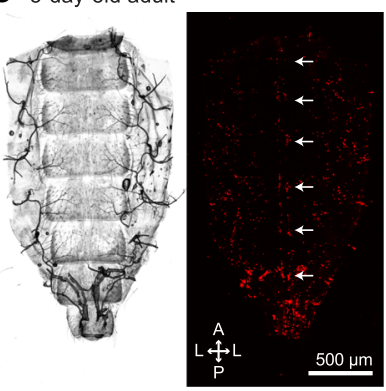

f 5-day-old adult

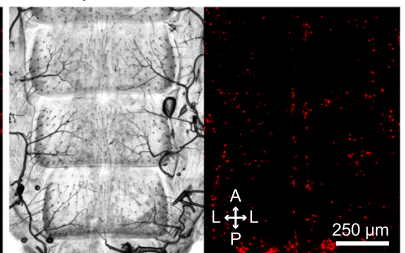

i Abdominal segment 5

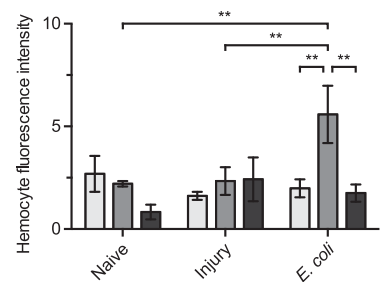

$\square$ Larva

$\square$ 1-day-old adult

5-day-old adult

Sidak's test:

* $\quad P<0.05$

Fig. 3 Sessile hemocyte arrangement and aggregation across life stages and in response to infection. a-f Dissected larva (a, d), 1-day-old adult $(\mathbf{b}, \mathbf{e})$ and 5-day-old adult (c, f) dorsal and lateral abdomens viewed under bright-field and fluorescence illumination at $24 \mathrm{~h}$ post-infection with $E$. coli. d-f show higher magnification images of segments 4, 5 and 6. Hemocytes were stained with CM-Dil (red). Larvae showed segmentally arranged hemocytes (box in a) as well as a high concentration of hemocytes in the 8th abdominal segment (circle in a). One-day-old adults showed an abundance of segmental hemocytes (box in b), including periostial hemocytes (arrows in $\mathbf{b}$ ). Five-day-old adults displayed a similar arrangement except that segmental hemocytes were more dispersed, and periostial hemocytes were more distinct (arrows in c). Directional arrows: A, anterior; P, posterior; L, lateral. g-k Total fluorescence intensity of CM-Dil-stained hemocytes from the dorsal and lateral abdomen for abdominal segments 2-8 combined (g) or from abdominal segments 4 (h), 5 (i), 6 (j) and 8 (k) alone in naïve, injured, and infected larvae, 1-day-old adults and 5-day-old adults at 24 h post-treatment. Quantitative data were analyzed by two-way ANOVA, followed by Šidák's post-hoc test. In $\mathbf{g - k}$, whiskers denote the SEM. Data for abdominal segments 2, 3 and 7 are presented in Additional file 3: Fig. S2 and data for hemocyte counts in abdominal segments 4, 5 and 6 (d-f) are presented in Additional file 4: Fig. S3

induced increase in sessile hemocytes of 1-day-old adults was due to strong increases in hemocyte intensity in segments 4, 5 and 6 (Fig. 3h-j), and to a lesser extent in the other abdominal segments (Additional file 3: Figure S2). In larvae, the fluorescence intensity of hemocytes was significantly elevated in the 8th abdominal segment, due to their strong association with the tracheal tufts, which is a phenotype not observed in adults (Fig. 3k).

To explore the abundance of sessile hemocytes on the dorsal and lateral abdominal wall in greater detail, we counted the number of hemocytes in segments 4, 5 and 6 and divided them by their anatomical location. We found that the infection-induced increase in sessile hemocytes in 1-day-old adults was due to an increase in the number of tracheal, cuticular, and periostial hemocytes relative to larvae and 5-day-old adults (Additional file 4: Figure S3; Šidák's: $P \leq 0.0001$ for all comparisons). Together, these results show that sessile hemocytes are numerous in larvae and adults, and that they increase in number after infection in newly-emerged adults. This 
infection-induced increase is particularly evident in the mid abdominal segments, which in adults is a region where there is high immune activity (for example, at the periostial regions) and high hemolymph flow [48, 55]. Furthermore, these findings confirm that the primary location of sessile hemocyte aggregation in larvae is at the tracheal tufts of the 8th abdominal segment, which are structures that surround the posterior openings of the larval heart [11].

\section{The phagocytic activity of individual hemocytes is higher} in adult mosquitoes compared to larvae

Our initial hypothesis postulated that changes in the abundance of hemocytes underscored the increased resistance of larvae and newly-emerged adults to a bacterial infection. However, differences in immune proficiency may also arise from differences in the frequency or degree to which hemocytes engage in phagocytosis. To test phagocytic activity across life stages, larvae and adults were infected with GFP-E. coli and the phagocytic activity of circulating hemocytes was quantified $1 \mathrm{~h}$ later. The phagocytic index, defined as the percentage of hemocytes that engage in phagocytosis following an immune challenge [45, 47], differed significantly between larvae, 1-day-old adults, and 5-day-old adults (Fig. 4a; Kruskal-Wallis: $H=33.94, d f=2, P<0.0001)$. Specifically, $60 \%, 75 \%$ and $85 \%$ of larval, 1-day-old adult and 5 -day-old adult hemocytes phagocytosed bacteria at $1 \mathrm{~h}$ post-challenge, respectively (Dunn's: $P \leq 0.0156$ for all comparisons). Phagocytic capacity, defined as the number of bacteria internalized by individual hemocytes, also differed significantly (Fig. 4b; Kruskal-Wallis: $H=1319$, $d f=2, P<0.0001)$, with larval, 1-day-old adult and 5 -day-old adult hemocytes containing an average of 2, 6 and 7 bacteria per cell, respectively (Fig. 4b; Dunn's $P<0$.0001 for all comparisons). When only hemocytes that phagocytosed bacteria were included in the analysis, a nearly identical pattern was observed (Fig. 4c; KruskalWallis: $H=1031, d f=2, P<0.0001$; Dunn's: $P \leq 0.0086$ for all comparisons). Interestingly, in addition to a Phagocytic index
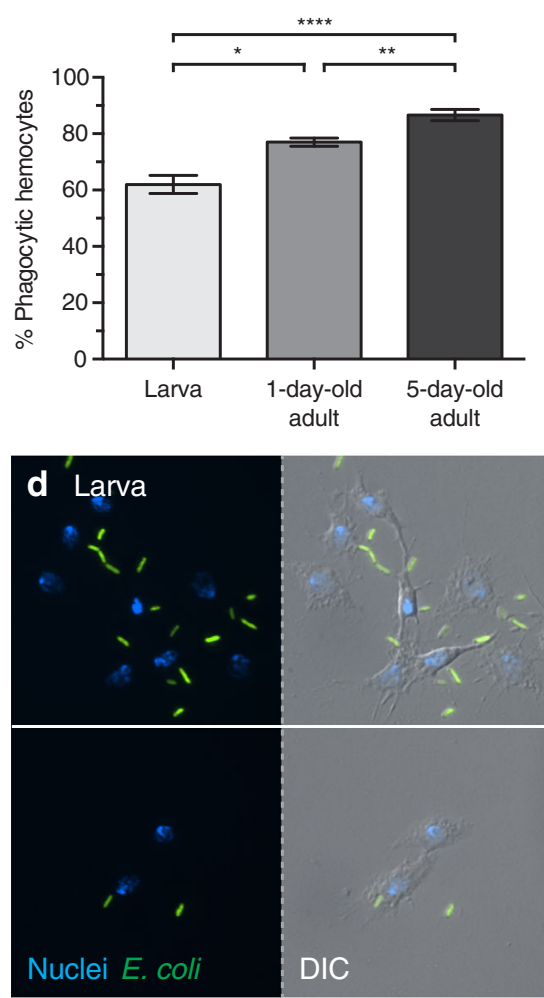

b Phagocytic capacity (all hemocytes)
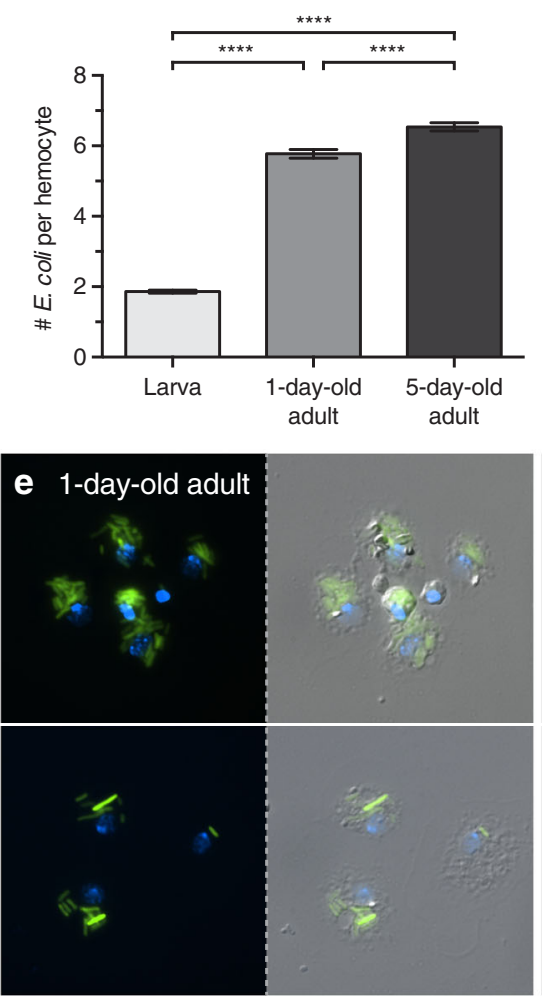

c Phagocytic capacity (phagocytic hemocytes)
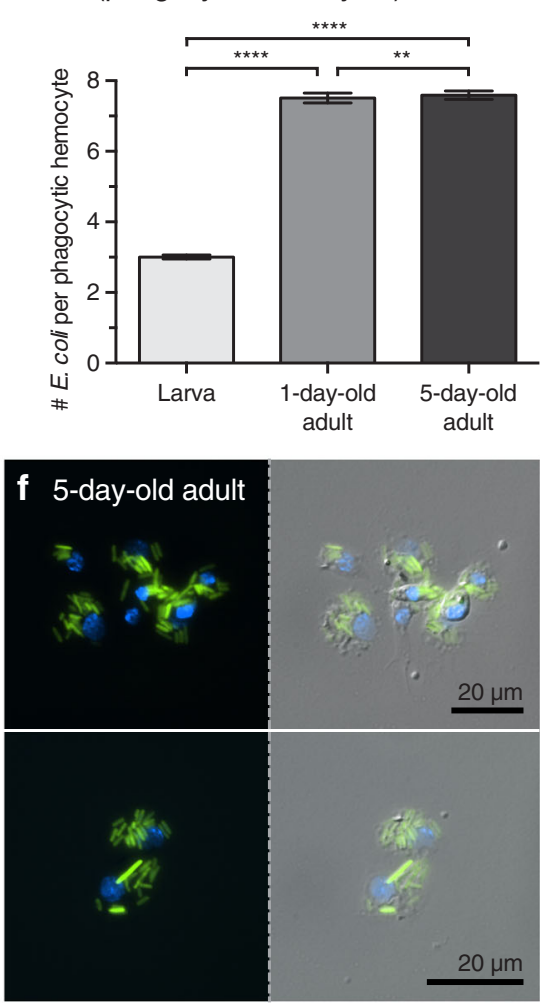

Fig. 4 Hemocyte phagocytic burdens and spread in adults and larvae. a Percentage of larval and adult hemocytes that phagocytosed bacteria at $1 \mathrm{~h}$ post-infection with E. coli (phagocytic index). b, c Number of bacteria in individual larval or adult hemocytes at $1 \mathrm{~h}$ post-infection (phagocytic capacity). Data were analyzed for all hemocytes observed (b), and for only the hemocytes that had engaged in phagocytosis (c). Data were analyzed by the KruskalWallis test, followed by Dunn's post-hoc test $\left.{ }^{*} P<0.05,{ }^{* *} P<0.01,{ }^{* * *} P<0.0001\right)$. In a-c whiskers denote the SEM. d-f Larval and adult hemocytes viewed under both fluorescence and DIC illumination. Phagocytosed GFP-E. coli (green) is contained within hemocytes whose nuclei have been stained with Hoechst 33342 (blue). Many larval hemocytes display fibroblast-like morphology (d), whereas hemocytes from newly-emerged adults (e) and older adults (f) display a more rounded spreading morphology 
differences in levels of phagocytosis, following infection many larval hemocytes displayed a fibroblast-like morphology with numerous filopodial extensions, which is different from the rounded morphology that is most often observed in adult hemocytes (Fig. 4d-f). Regardless of shape, these hemocytes are phagocytic suggesting that, similar to what we and others have found for adults $[26,56,57]$, the vast majority of larval hemocytes are granulocytes. Together, these data show that, upon an identical bacterial challenge, the phagocytic burden of individual circulating hemocytes is higher in adults than it is in larvae (Fig. 4), although larvae contain more circulating hemocytes than adults (Fig. 2).

Hemolymph from immune stimulated larvae has stronger antibacterial activity than hemolymph from adults

In response to infection, mosquitoes produce humoral immune factors that lyse pathogens $[1,7,9,10,58]$. To test whether the enhanced immunity we observed in mosquito larvae is correlated with enhanced humoral antimicrobial activity in their hemolymph, we employed a zone of inhibition assay to measure the general antibacterial activity of hemolymph.

In trials involving heat-killed $E$. coli, the antibacterial activity of hemolymph differed significantly between larvae, 1-day-old and 5-day-old adults (Fig. 5a, b; two-way ANOVA: $\left.F_{(2,63)}=19.82, P<0.0001\right)$. This was due to the significantly higher antibacterial activity of larval hemolymph compared to both adult groups (Šidák's:
$P \leq 0.0001$ for both comparisons), and not to a difference between 1-day-old and 5-day-old adults (Šidák's: $P=0.8717)$. Furthermore, this difference in antibacterial activity was due to an induced response, rather than a constitutive response, as the antibacterial activity in the hemolymph of naïve and injured individuals did not differ between larvae and adults, with the exception of when injured larvae were compared to 1-day-old adults (Šidák's: $P=0.0387$ ). To test whether this finding was unique to immune stimulation with Gram (-) E. coli, we repeated the experiment by stimulating mosquitoes with heat-killed Gram (+) M. luteus (Fig. 5c, d) and heatkilled Gram (-) Enterobacter sp. isolate Ag1 (Fig. 5e-f), a bacterial strain that naturally colonizes the midgut of $A$. gambiae and is a core adult bacterial symbiont taxon $[43,44]$. In both sets of experiments, antibacterial activity of hemolymph was significantly higher in larvae compared to adults (Fig. 5d, F; two-way ANOVA: $F_{(2}$, 59) $=13.06, P<0.0001$ for $M$. luteus and $F_{(2,65)}=13.17$, $P<0.0001$ for Enterobacter sp.; Šidák's: $P \leq 0.0252$ for all comparisons). This resulted from an induced response, as the antibacterial activity of hemolymph from naïve and injured mosquitoes did not differ between larvae and adults (Šidák's: $P \geq 0.2856$ for all comparisons). Although, based on these data it would be tempting to state that the immune system can discern between Gram $(-)$ and Gram (+) bacteria because of the strength of the response, in this case it would be incorrect to do so because the doses and levels of pathogenicity are not

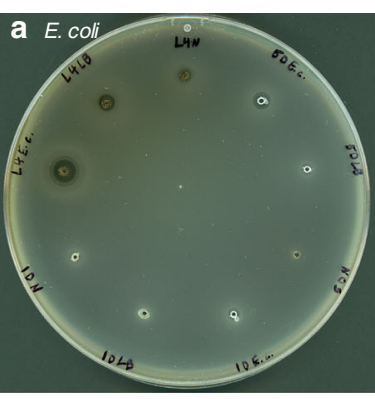

b E. coli

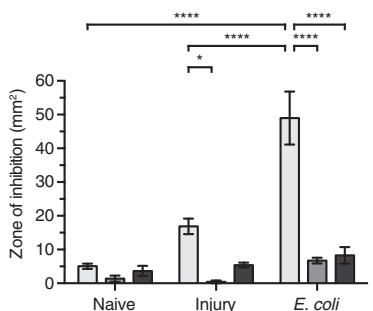

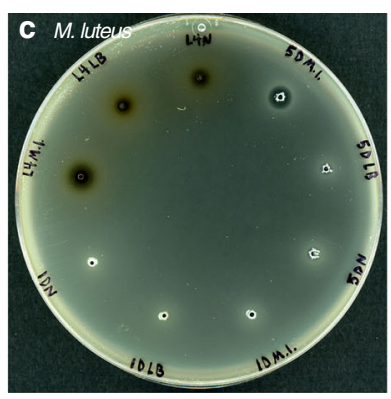

d M. luteus

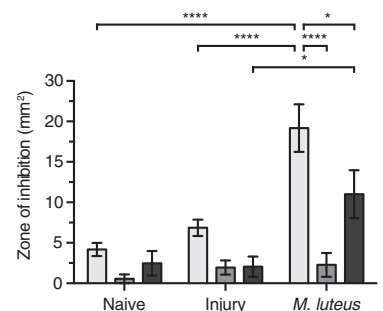

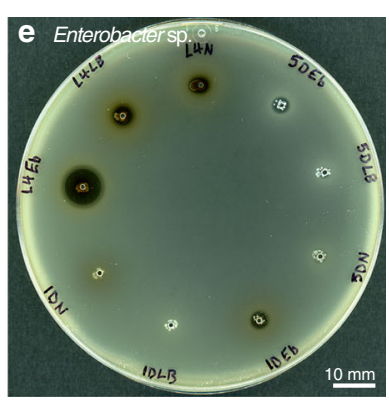

f Enterobactersp.

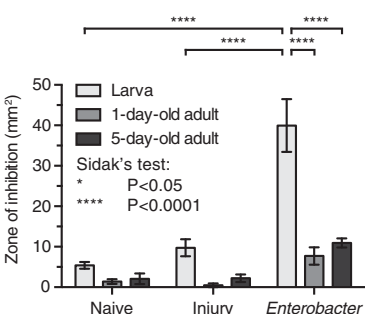

Fig. 5 Larval and adult antibacterial humoral immunity. a, b Zone of inhibition plating assay (a), including quantitative measurement of the zones of inhibition (b), showing the extent of hemolymph lytic activity in mosquitoes that were naïve, injured, or challenged with heat-killed E. coli $24 \mathrm{~h}$ earlier. c-f Similar experiment except using heat-killed M. luteus (c, d) or heat-killed Enterobacter sp. (e, f) as the challenge agent. In $\mathbf{b}$, d, and f, data were analyzed by two-way ANOVA, followed by Šidák's post-hoc test. Whiskers denote the SEM. Hand-written abbreviations on the plates: L4, fourth-instar larvae; 1D, 1-day-old adult; 5D, 5-day-old adult; N, naïve; LB, injured; E.c., E. coli; M.I., M. luteus; Eb, Enterobacter 
equivalent across the different bacteria species. Together, these experiments show that the strength of humoral antibacterial activity of hemolymph is stronger in larvae compared to adults.

\section{Phenoloxidase activity is higher in larvae compared to adults}

While conducting experiments measuring the antibacterial activity of hemolymph, we noticed that hemolymph, especially from larvae, had a tendency to darken rapidly after extraction, a phenomenon suggestive of the activation of phenoloxidase-mediated melanization. Because melanization is a major component of the humoral immune response of mosquitoes [59], we tested the relative strength of melanization in larval and adult hemolymph using a phenoloxidase activity assay $[60,61]$ that relies on the conversion of L-DOPA to dopachrome by phenoloxidase, a rate limiting enzyme in the melanization pathway $[59,62]$.

Measurements of the absorbance of diluted hemolymph (1:500 final dilution) incubated with L-DOPA, taken every $5 \mathrm{~min}$ for $30 \mathrm{~min}$, showed that phenoloxidase activity differs significantly between life stages (Fig. 6a, b; repeated measures two-way ANOVA: $\left.F_{(9,40)}=62.99, P<0.0001\right)$. Specifically, the phenoloxidase activity of larval hemolymph was significantly higher at all time points measured when compared to 1-day-old and 5-day-old adults (Šidák's: $P \leq 0.0263$ for all 5 min comparisons and $P<0.0001$ for all 10-30 min comparisons). Phenoloxidase activity is a constitutive response, rather than an induced response, because no differences in phenoloxidase activity were detected between the hemolymph of naive, injured and infected larvae or 1-day-old adults (Šidák's: $P>0.9999$ for all comparisons). In 5-day-old mosquitoes, infection reduced the melanization activity of hemolymph, with statistically significant differences beginning at the $20 \mathrm{~min}$ time point, suggesting that at the time of hemolymph collection the enzymatic cascade was partially depleted by immune responses during the ongoing infection (Šidák's: $P \leq 0.0335$ for all but two of six pairwise comparisons). No melanization activity was detected when L-DOPA was incubated in water in the absence of hemolymph, confirming that L-DOPA was not undergoing autooxidation (Fig. 6a; Additional file 5: Figure S4; Šidák's: $P>0.9999$ for all comparisons).

To quantify the melanization of endogenous substrates in diluted hemolymph, as opposed to the conversion of exogenous L-DOPA as in the above experiment, we repeated the experiment by diluting hemolymph samples in water alone, without L-DOPA. As expected, because of the absence of exogenous substrate, the absorbance values in all samples were very low (Additional file 5: Figure S4a). Nevertheless, larval hemolymph was significantly darker than adult hemolymph (Additional file 5: Figure S4b; Šidák's: $P \leq 0.0086$ for all comparisons), and no change in melanization occurred when comparing the initial and final readings, indicating that by the initial reading all endogenous substrates had been consumed in melanization reactions (Šidák's: $P \geq 0.1690$ for all comparisons).

Finally, to ensure that the darkening of hemolymph did not occur because of the activity of enzymes other than phenoloxidase, including iron-based peroxidase and
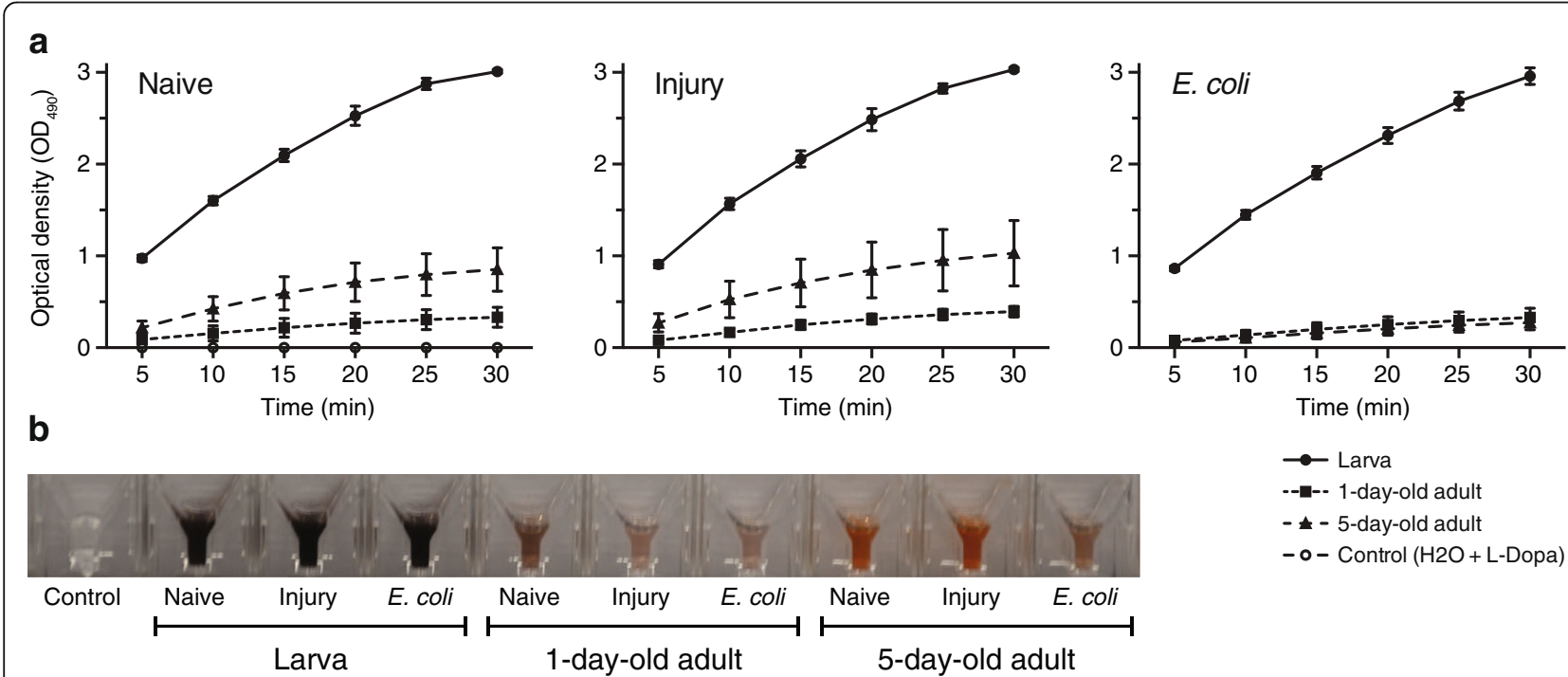

Fig. 6 Hemolymph phenoloxidase activity of larvae and adults. a Time course of optical density $\left(\mathrm{OD}_{490}\right)$ measurements of hemolymph from naïve, injured, and E. coli-infected larvae, 1-day-old adults, and 5-day-old adults that was diluted in water containing L-DOPA. Data were analyzed by two-way ANOVA, followed by Šidák's multiple comparisons post-hoc test. Regardless of treatment and time point, larvae showed higher phenoloxidase activity than 1-day-old and 5-day-old adults (Šidák's: $P \leq 0.0263$ for all comparisons). Whiskers denote the SEM. $\mathbf{b}$ Images of cuvette wells at the 30 min time point showing that melanization-induced darkening is more pronounced in the larval samples 
catalase [59], we mixed diluted hemolymph with a solution containing both L-DOPA and diethyldithiocarbamate (DETC), a copper-specific chelator that inhibits copper-based phenoloxidase [59, 63-65]. Although larval hemolymph was again significantly darker than adult hemolymph because of the rapid melanization of endogenous (Additional file 5: Figure S4c, d; Šidák's: $P \leq 0.0013$ for all comparisons), melanization levels did not change following the addition of the solution of LDOPA and DETC (Šidák's: $P \geq 0.5840$ for all comparisons), confirming that the melanization activity of hemolymph is driven by the activity of phenoloxidase. Together, these findings demonstrate that larval hemolymph contains greater melanization potential than adult hemolymph, and that this is due to the activity of phenoloxidase.

\section{Infection-induced transcriptional upregulation of} immunity-related genes is higher in larvae than in adults To determine whether larvae and differently aged adults differ with respect to the expression of immunity genes, relative mRNA fold change was assayed by qPCR at $24 \mathrm{~h}$ post-treatment in naïve, injured, and $E$. coli-infected larvae, 1-day-old adults and 5-day-old adults (Fig. 7; Additional file 6: Figure S5; Additional file 7: Figure S6; Additional file 2: Table S1). A broad range of immune responses was surveyed by measuring the transcription of 24 immunity genes representing four major categories of immune function: (i) pathogen recognition, specifically CTL4 [66-68], FREP13 [12, 69], GNBPB4 [70], TEP1 [71, 72], Eater, Nimrod, and Draper [73], and SCRBQ2 [74, 75]; (ii) signal modulation, specifically CLIPB15 [12, 22, 66] and SRPN6 [76, 77]; (iii) signal transduction, specifically Toll pathway members MYD88 and CACTUS [12, 78, 79], Imd pathway members CASPL1 and CASPAR [80], and Jak/Stat pathway members AGSTAT-A and PIAS [14, 81, 82]; and (iv) effector responses, specifically CECA [12, 20, 83], GAM1 [12, 21], DEF1 [12, 28, 30, 84, 85], PPO1 [12, 16, 86, 87], PPO6 [16, 86], LYSC1 [15, 88-90], NOS [91], and DUOX [92-95]. In addition, the expression of two genes involved in the ecdysteroid biosynthetic pathway, CYP302A1 and CYP315A1 [96, 97], was measured, as ecdysone peaks in the late larval and pupal stages and ecdysone induces the transcriptional upregulation of phenoloxidase genes in an A. gambiae hemocyte-like cell line [16, 87]. RPS7 was used as the reference gene, and RPS17 was used as a control [45].

In larvae, 17 immunity genes were either strongly (greater than 2-fold: 11) or weakly (between 1.5 and 2-fold: 6) upregulated by infection relative to naive larvae, whereas in 1-day-old and 5-day-old adults, only 13 (11 strongly and 2 weakly) and 10 (9 strongly and 1 weakly) immunity genes were upregulated by infection, respectively, relative to naïe

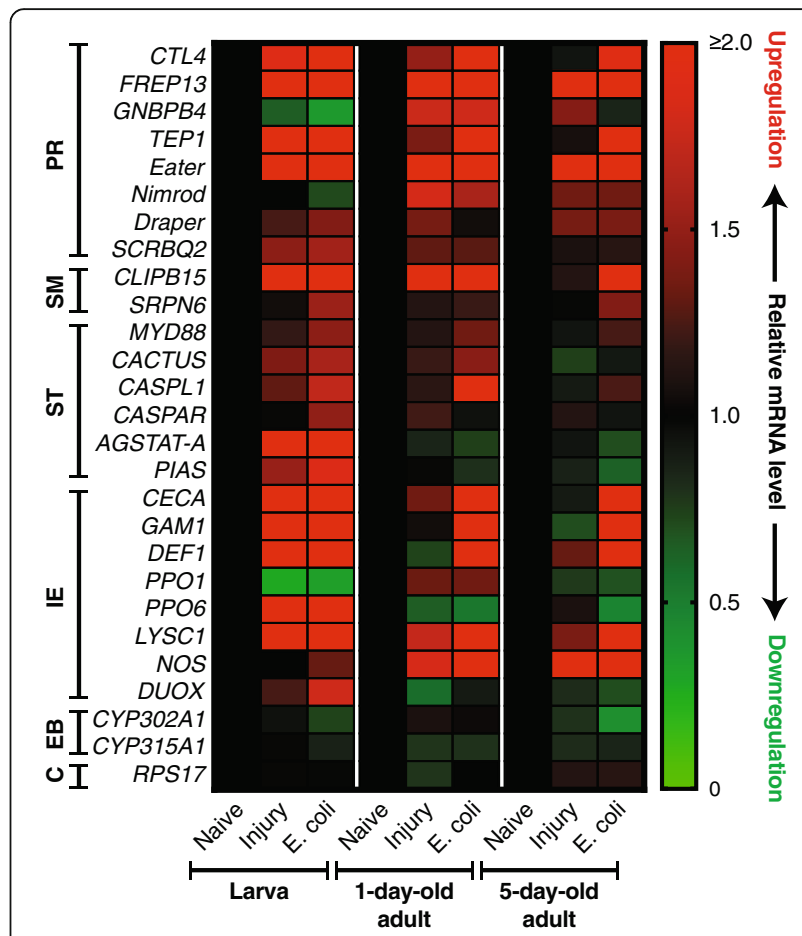

Fig. 7 Infection-induced transcriptional regulation in larvae and adults. Heat map showing the average relative mRNA fold change of immunityrelated genes in naïve, injured, and E. coli-infected larvae, 1-day-old adults and 5-day-old adults. Data are normalized against naïve individuals of the same age. Red color indicates upregulation, green indicates downregulation, and black indicates no regulation (see scale on right). For detailed graphs for each gene, see Additional file 6: Fig. S5 and Additional file 7: Fig. S6. Abbreviations: PR, pathogen recognition; SM, signal modulation; ST, signal transduction; IE, immune effectors; EB, ecdysteroid biosynthesis; $C$, control. In order, gene IDs from www.vectorbase.org are: AGAP005335, AGAP011197, AGAP002796, AGAP010815, AGAP012386, AGAP009762 (renamed AGAP029054), AGAP007256, AGAP010133, AGAP009844, AGAP009212, AGAP005252, AGAP007938, AGAP011693, AGAP006473, AGAP010423, AGAP005031, AGAP000693, AGAP008645, AGAP011294, AGAP002825, AGAP004977, AGAP007347, AGAP008255, AGAP009978, AGAP005992, AGAP000284 and AGAP004887

adults of their respective age (Fig. 7; Additional file 6: Figure S5; Additional file 7: Figure S6; Table 1). Transcription of ecdysteroid biosynthesis genes and, as expected, RPS17 was not regulated by infection in any age group. In general, larvae and adults showed a similar level of infection-induced induction of some pathogen recognition and signal modulation genes, as well as some immune effector genes, such as cecropin (CECA), gambicin (GAM1), defensin (DEF1) and lysozyme (LYSC1). However, injury tended to result in a higher level of transcriptional induction in larvae when compared to adults.

When comparing the levels of induction, larvae showed greater than 2-fold higher induction (that is, the fold change of the larval group divided by the fold change of the adult group was >2) of AGSTAT-A, PIAS, $P P O 6$, and dual oxidase $(D U O X)$ relative to both adult 
Table 1 Summary of comparative immune data arising from experiments on larvae, 1-day-old adults, and 5-day-old adults. High, medium, and low responses are relative designations assigned by comparing each group to the other two groups and ranking them based on the strength of the response

\begin{tabular}{|c|c|c|c|}
\hline & Larva & 1-day-old adult & 5-day-old adult \\
\hline Bacterial killing & High & High & Low \\
\hline $\begin{array}{l}\text { Number of circulating hemocytes } \\
\text { (increase after infection?) }\end{array}$ & High (Yes) & Medium (No) & Low (No) \\
\hline $\begin{array}{l}\text { Number of sessile hemocytes } \\
\text { (increase after infection?) }\end{array}$ & Medium (No) & High (Yes) & Low (No) \\
\hline Phagocytic burden & Low & High & High \\
\hline $\begin{array}{l}\text { Integrated immune and circulatory } \\
\text { systems }\end{array}$ & Yes, at the tracheal tufts & Yes, at the periostial regions & Yes, at the periostial regions \\
\hline Antimicrobial activity of hemolymph & High & Low & Low \\
\hline Phenoloxidase activity of hemolymph & High & Low & Medium \\
\hline Immune gene induction & High & Medium & Low \\
\hline $\begin{array}{l}\text { Genes transcriptionally upregulated } \\
>2 \text {-fold (strongly) }\end{array}$ & $\begin{array}{l}\text { CTL4, FREP13, TEP1, Eater, CLIPB15, } \\
\text { AGSTAT-A, CECA, GAM1, DEF1, PPO6, } \\
\text { LYSC1 }\end{array}$ & $\begin{array}{l}\text { CTL4, FREP13, TEP1, Eater, CLIPB15, } \\
\text { CASPL1, CECA, GAM1, DEF1, LYSC1, } \\
\text { NOS }\end{array}$ & $\begin{array}{l}\text { FREP13, TEP1, Eater, CLIPB15, } \\
\text { CECA, GAM1, DEF1, LYSC1, NOS }\end{array}$ \\
\hline $\begin{array}{l}\text { Genes transcriptionally upregulated } \\
1.5-2 \text {-fold (weakly) }\end{array}$ & $\begin{array}{l}\text { SCRBQ2, SRPN6, CACTUS, CASPL1, } \\
\text { PIAS, DUOX }\end{array}$ & GNBPB4, Nimrod & CTL4 \\
\hline $\begin{array}{l}\text { Genes transcriptionally downregulated } \\
<0.5 \text {-fold (strongly) }\end{array}$ & GNBPB4, PPO1 & None & PPO6, CYP302A1 \\
\hline
\end{tabular}

groups, and this was due to infection causing transcriptional upregulation of these genes in larvae and weak transcriptional downregulation in adults. Both adult groups showed greater than 2-fold higher induction of nitric oxide synthase (NOS) and a fibrinogen-related protein gene (FREP13, also known as $F B N 9$ ) relative to larvae, and 1-day-old adults showed greater than 2-fold higher induction of a CLIP domain serine protease (CLIPB15) relative to larvae, despite FREP13 and CLIPB15 being greater than 2-fold upregulated in response to infection in both life stages (Fig. 7; Additional file 6: Figure S5; Additional file 7: Figure S6).

In addition to differences in the level of induction of specific immunity genes across life stages, some genes were only upregulated in a single life stage. For example, infection in larvae, but not adults, induced the upregulation of Jak/Stat essential pathway genes AGSTAT-A and PIAS, as well as the immune effectors PPO6 and DUOX. Conversely, infection in adults, but not larvae, strongly induced the upregulation of NOS. Interestingly, although the Gram (-) binding protein gene, GNBPB4, was transcriptionally downregulated in larvae following infection, when all the data were instead normalized against naïve 5-day-old adults, basal expression of GNBPB4 in naïve larvae was 470- and 710-fold higher than in naïve 1-day-old and 5-day-old adults, respectively. A similar finding was made with respect to one of the phenoloxidase genes assayed, PPO1, which was expressed 170- and 110 -fold higher in naïve larvae relative to naïve 1 -day-old and 5-day-old adults, respectively. Collectively, these data show that induction of immunity genes differs with life stage and adult age, with infection-induced expression being highest in larvae and declining shortly after eclosion and as adults age.

\section{Discussion}

Mosquitoes are susceptible to infections during all stages of their life cycle, and in response have evolved a robust innate immune system [1]. Mosquitos acquire pathogens via ingestion and through breaches in the outer cuticle, such as during injury. For example, larvae acquire Bacillus thuringiensis while feeding in their aquatic environment, and adults acquire Plasmodium sp. while imbibing infected vertebrate blood [10, 98]. Because the adult stage is responsible for the transmission of diseasecausing pathogens such as malaria [9, 10], the vast majority of research on mosquito immunology has focused on that life stage, and in particular, on the adult females that feed on blood. In contrast, research on the immune system of the larvae of other insects, such as Manduca sexta, Bombyx mori and Drosophila melanogaster has proven invaluable for uncovering fundamental aspects of the cellular and humoral immune response of insects, and animals in general [99-101]. Nevertheless, lacking in Insecta are comparative studies that examine differences in immunity across the different life stages of a given species. As noted by Fellous \& Lazzaro, "Almost all studies of the immune system of animals with metamorphosis have focused on either larval or on adult immunity, implicitly assuming that these traits are either perfectly correlated or evolutionarily independent" [41]. Because mosquito larvae live in aquatic environments 
rife with microorganisms and survival through the larval stages is required to reach sexual maturity, at the onset of this study we hypothesized that larvae have evolved more proficient means of neutralizing infections than adults. To compare larval and adult immunity in $A$. gambiae, we measured a broad range of immune parameters that were previously unexamined in larvae, and show that immune activity is strongest in larvae and wanes in the adult life stage (Table 1). Furthermore, because immunity phenotypes differ between life stages that are separated by metamorphosis, these findings suggest that adaptive decoupling, or the independent evolution of larval and adult traits made possible by metamorphosis [40], has occurred in A. gambiae.

Evidence for adaptive decoupling has been found in a broad range of animals with complex life cycles, including amphibians, fish, marine invertebrates and insects $[40,41,102-108]$. Several lines of evidence suggest that adaptive decoupling of immune responses has also occurred in the mosquito lineage. First, we have shown that the strength and composition of the mosquito immune response differs between immature larvae, newly-emerged adults and reproductively active older adults. Secondly, we have previously shown $[11,48,55]$, and recapitulate here, that the mosquito circulatory and immune systems display stage-specific functional integration, enabling functionally analogous, yet anatomically disparate, immune strategies in larvae and adults. Thirdly, mosquitoes have complex life cycles with ecologically distinct larval and adult stages that are subject to different selection pressures, due to differences in pathogen exposure and reproductive status. Thus, we expect that a decoupling of key traits between these life stages, which are separated by metamorphosis, is advantageous to both stages in responding independently to differing selection pressures and in the performance of different fitness tasks (for example, food consumption and growth in larvae and reproduction in adults). Taken together, these arguments suggest that adaptive decoupling has occurred in mosquitoes, enabling the independent evolution of key larval and adult immune traits.

Our data show that larvae kill bacteria at a higher rate, possess more circulating hemocytes, have higher lytic and melanization activity in their hemolymph and have higher infection-induced expression of immunity genes than adults, thus strongly supporting our hypothesis that mosquito larvae invest more into immunity than adults. In our view this is not surprising; larvae inhabit bacteria-rich environments and display higher gut microbial diversity than adults [44, 109], suggesting that mosquitoes are exposed to a higher density and diversity of bacteria as larvae than as adults, and require more robust immune responses as larvae, as has been hypothesized previously [110]. Thus, given the vastly different ecologies between larvae and adults, coupled with the fact that evolutionary pressures are strongest on younger individuals that have yet to reach their reproductive potential $[34,35]$, we hypothesize that the stronger selection pressures at work in the larval stage, compared to the adult stage, have over time caused larvae to invest more greatly in immunity than adults.

Our findings on immune proficiency in larvae and adults is also indicative of immune senescence, as immunity in larvae is stronger than in adults, and immunity continues to weaken after metamorphosis, with 5-day-old adults mounting weaker immune responses than adults that were 4 days younger. This finding is consistent with well-attested evolutionary theories of senescence, which state that greater selection pressures are at work in the larval stage to ensure survival to the reproductively mature adult life stage $[34,36]$. According to the "Disposable Soma" theory of aging, this occurs, in part, due to immune trade-offs that would not be in play at the larval stage, particularly those related to reproduction [111]. For example, resistance to pathogens in adult mosquitoes has been associated with reproductive costs [112-115]. Furthermore, numerous studies have documented age-associated declines in immune functions in mosquitoes [13, 26, 46, 47, 110, 116-120], fruit flies [121-123], butterflies [124, 125], bees [126-130], and other insects [131-135]. However, unlike these earlier studies, which focused almost exclusively on adults, our findings show that this trend extends into the earlier larval life stage. This suggests that mosquito adults employ a "live fast, die young" life history strategy [136], whereby immunity declines and mortality increases after adults reach reproductive maturity and selection for their survival wanes [34].

Although the data presented in this study conclusively show that larvae mount a stronger immune response than adults against bacteria that are present in the hemocoel, the adult stage has evolved mechanisms to boost the immune system when the possibility of infection is anticipated. Mainly, because many adult infections begin with an infectious blood meal $[6,10,137]$, adult mosquitoes boost their immune reserves upon ingestion of blood. For example, in both mosquito subfamilies, acquisition of a blood meal induces the replication of hemocytes even in the absence of infection [138-140]. Whether this has a positive impact on the ability of anopheline mosquitoes to respond to an infection in the hemocoel remains unknown, but for $A$. aegypti (a culicine mosquito), blood feeding improves the ability to combat a low dose E. coli infection but is detrimental when facing a high dose $E$. coli infection [140].

The age-dependent decrease in immune proficiency correlates with age-related changes in the number of circulating hemocytes present in the hemocoel. We found that mosquito larvae contain more circulating hemocytes than 
adult mosquitoes, and that the number of larval hemocytes increases in response to infection. This is consistent with earlier studies conducted in Anopheles gambiae and Aedes aegypti adults that showed that immune stimulation or blood-feeding increases the number of circulating hemocytes $[26,45,86,138-142]$, and that the number of circulating hemocytes declines with adult age [26, 46, $47,116]$. Hemocytes are the first cellular responders to infection, phagocytosing pathogens in larvae and adults within minutes of infection [11, 48, 55, 57, 143, 144], and producing factors that limit both bacteria and Plasmodium infection [66, 86, 137, 145]. Thus, developmental changes in hemocyte profiles in part explain the higher bacteria killing efficiency of larvae relative to adults.

Although sessile hemocytes were abundant in both larvae and adults, the spatial arrangement of sessile hemocytes differed as adults aged, with newly-emerged adults displaying a pronounced segmental arrangement of hemocytes, which is more akin to what is observed in larvae than what is observed in 5-day-old adults $[11,46]$. Furthermore, whereas hemocytes in adults aggregate at the periostial regions of the heart, hemocytes in larvae aggregate in the tracheal tufts of the 8th abdominal segment, where the sole incurrent openings into the heart is located. These differences are due to the stage-specific functional integration of the immune and circulatory systems, as hemocytes aggregate in the areas of highest hemolymph flow [11, 46, 48, 55]. These differences may also be explained by stage- and age-specific changes in heart physiology $[42,146]$. Overall, these data show that sessile hemocyte populations undergo developmentallyrelated changes in spatial configuration and infectioninduced abundance.

The finding that larvae have more circulating hemocytes than adults may account for the seemingly counterintuitive finding that larvae show lower phagocytic indices and capacities than adults. This is because larvae have more hemocytes available to phagocytose pathogens than adults, and based on our finding on the lytic and melanization activity of hemolymph, they also have a greater recourse to other means of pathogen clearance. Thus, an accumulation of phagocytic events in adults may signify a greater need for this immune mechanism, or lower phagocytic turnover rates, which has also been observed in aging fruit fly adults [121]. Interestingly, these differences in phagocytosis are accompanied by changes in hemocyte morphology. Larval hemocytes often had a fibroblast-like spread morphology, which has been observed in other insect hemocytes [27, 147], as opposed to the more rounded spread morphology typical of mosquito adult hemocytes $[26,46,48,56,57,143]$. These fibroblast-shaped hemocytes have the functional characteristics of granulocytes, which are phagocytic, and not the functional characteristics of oenocytoids, which are the major producers of the phenoloxidase enzymes that drive the melanization pathway $[3,56,57]$.

In addition to stage-specific differences in hemocyte biology, we detected profound differences in the melanization activity of hemolymph. Melanization is commonly used in the immune response against bacteria, malaria, and filarial worms $[2,7,59,148]$, and we found that mosquito larvae display a far greater capacity for phenoloxidase-mediated humoral melanization than adults. This finding is consistent with our recent observations of rapid and extensive melanin deposits in the abdomen of larvae following a bacterial infection [11], as well as with the decline in phenoloxidase activity that occurs with adult age in Aedes aegypti [117], and across life stage and with adult age in Culex pipiens [110]. In addition to enhancing humoral immunity, larvae may increase the melanization activity of hemolymph in preparation for cuticle tanning during and immediately after ecdysis, and for the rapid melanization of wounds in the more perilous aquatic environment of larvae.

In our final set of experiments, we show that immunity gene induction is generally stronger in larvae compared to adults, with the difference being exacerbated as adults age, and that larvae and adults differentially regulate the expression of some immunity genes. The higher rate of $E$. coli killing in larvae is consistent with the expression of immune effector genes such as the Gram (-) binding protein gene, GNBPB4, which was expressed 470- and 710-fold higher in naïve larvae compared to naïve 1-day-old and 5-day-old adults, respectively, as well as the higher expression of the phenoloxidase gene PPO1, which was expressed 170- and 110-fold higher in larvae relative to naïve 1-day-old and 5-day-old adults, respectively. The higher rate of melanization we observed in larval hemolymph is also consistent with the higher PPO6 gene induction we observed in larvae, and supports our previous finding of higher infection-induced melanization in the abdomen of larvae when compared adults [11]. Furthermore, the higher melanization activity in the hemolymph of larvae is also consistent with the high level of dual oxidase $(D U O X)$ gene induction detected in this life stage, as increased reactive oxygen species levels have been correlated with increased melanization [93]. In addition to the immune effector genes PPO6 and DUOX, we also found that the Jak/Stat essential pathway member $A G S T A T-A$ and, to a lesser extent, the negative regulator of this pathway, PIAS, were induced in response to $E$. coli infection in larvae and not in adults, showing that the same infection results in stage-specific induction of signaling pathway genes. The upregulation of Imd pathway member CASPL1 in larvae and 1-day-old adults is consistent with this pathway's role in combating Gram (-) bacterial infections, however the cause for Jak/Stat pathway involvement in the larval response alone is unknown, 
though it may have to do with its function in mosquito development [82], as this pathway is involved in Drosophila development [149]. Adults, not larvae, showed distinct upregulation of nitric oxide synthase, an important component of the adult immune response [91, 150], as well as higher upregulation of the pathogen recognition gene FREP13 and the signal modulation gene CLIPB15. These differences in immunity gene induction across life stages could result from changes in the tissues expressing these genes during metamorphosis, as has been hypothesized previously $[28,41]$. More broadly, however, these differences in immune gene regulation in larvae and adults are suggestive of adaptive decoupling, which would permit the independent regulation of larval and adult immune gene expression [40, 41].

Although the data presented herein show the formidable strength of the larval immune system relative to that of adults, these data were collected following the intrahemocoelic injection of a facultative pathogen, and not following feeding of an obligate pathogen. The route of administration and choice of pathogen was necessary to ensure that an identical dose with a known pathogen was provided to all groups, and to establish a precise time of infection. While many pathogens, including bacteria and entomopathogenic fungi, invade the hemocoel directly through the cuticle, future studies focusing on infections via the gut should be conducted to complement and refine our understanding of the present work. Furthermore, although this study did not track longterm mosquito survival (the larvae begin to pupate after $24 \mathrm{~h}$ ), the long-term consequence of larval infection in the adult stage is an important gap in our current understanding and is an ongoing topic of study in our research group. Finally, our experiments on hemocyte biology did not differentiate between granulocytes, oenocytoids, or prohemocytes due to limitations inherent to the cell staining method, but it is well established that approximately $95 \%$ of hemocytes are granulocytes [3], and our qualitative observations suggest that life stage does not impact the proportion of hemocyte types.

\section{Conclusions}

Studying larval immunity is crucial to our general understanding of mosquito biology, disease transmission, and vector control for several reasons. First, because mosquitoes are holometabolous insects, studying the larval immune system could yield important insights into how immune responses change over the course of development [11]. Secondly, larval environmental factors, including food availability, temperature, population density, competition and chemical insecticide exposure [151-159], as well as exposure to bacterial and fungal pesticides [98, 160-166], have all been shown to impact adult vector competence. Thirdly, many of the most widespread and effective mosquito control methods directly target the larval stages [167-169], and resistance to insecticides evolves more rapidly in larvae compared to adults, likely due to the stronger selection pressures at work in the larval stage [35]. The present study highlights both continuities and discontinuities between the larval and adult immune systems, and shows that mosquito larvae possess an enhanced immune system compared to adults. Hence, understanding the larval immune system of Anopheles gambiae, a major vector of malaria in SubSaharan Africa, could prove critical to the development and implementation of novel pest and disease control methods that are tailored to each life stage.

\section{Additional files}

Additional file 1: Figure S1. Fluorescence emitted by sessile hemocytes in larvae and adults was measured using custom-drawn regions of interest. Representative images of dissected larva (a), 1-day-old adult (b) and 5-dayold adult (c) dorsal and lateral abdomens imaged under bright-field and fluorescence illumination at $24 \mathrm{~h}$ post-infection with E. coli. Hemocytes were stained with CM-Dil (red). Seven custom regions of interest (ROIs), encompassing abdominal segments $2-8$, were used to quantify mean fluorescence intensity of CM-Dil stained hemocytes. ROls delineated the dorsal (tergum) and lateral (pleuron) abdominal cuticle that lies between the abdominal sutures of adjoining abdominal segments. Directional arrows: A, anterior; P, posterior; L, lateral. (PDF $466 \mathrm{~kb}$ )

Additional file 2: Table S1. Gene names, VectorBase gene IDs, and primers used for quantitative RT-PCR. (PDF $30 \mathrm{~kb}$ )

Additional file 3: Figure S2. Sessile hemocytes are present in abdominal segments 2, 3 and 7. Fluorescence intensity of CM-Dil-stained hemocytes in abdominal segments 2 (a), 3 (b), and 7 (c) of naïve, injured, and E. coli-infected larvae, 1-day-old adults and 5-day-old adults at $24 \mathrm{~h}$ post-treatment. Quantitative data were analyzed by two-way ANOVA, followed by Šidák's post-hoc test. Whiskers denote the SEM. Data for abdominal segments 4, 5, 6 and 8 are presented in Fig. 3. (PDF $116 \mathrm{~kb}$ )

Additional file 4: Figure S3. Sessile hemocytes in abdominal segments 4, 5 and 6 vary in response infection. Total number of CM-Dil-stained hemocytes attached to the trachea (a), cuticle (b, integument) and periostial regions of the heart (c) in abdominal segments 4, 5 and 6 of naïve, injured, and E. coli-infected larvae, 1-day-old adults and 5-day-old adults at $24 \mathrm{~h}$ post-treatment. Data were analyzed by two-way ANOVA, followed by Šidák's post-hoc test. Whiskers denote the SEM. (PDF 122 kb)

Additional file 5: Figure S4. Endogenous melanization is highest in larvae, and exogenous melanization is completely inhibited by DETC. a, b Time course of optical density $\left(\mathrm{OD}_{490}\right)$ measurements of hemolymph from naïve, injured, and E. coli-infected larvae, 1-day-old adults and 5-dayold adults diluted in water. The scale in $\mathbf{a}$ is amplified and separated by treatment in b. Larval hemolymph was significantly darker than adult hemolymph (Šidák's: $P \leq 0.0086$ for all comparisons) and melanization levels did not change when comparing the initial and final readings of any age or treatment group (Šidák's: $P \geq 0.1690$ for all comparisons). c, $\mathbf{d}$ Time course of optical density $\left(\mathrm{OD}_{490}\right)$ measurements of hemolymph from naïve, injured, and E. coli-infected larvae, 1-day-old adults and 5-dayold adults diluted in saturated L-DOPA with DETC, which is a phenoloxidase inhibitor. The scale in $\mathbf{c}$ is amplified and separated by treatment in $\mathbf{d}$. Larval hemolymph was significantly darker than adult hemolymph (Šidák's: $P \leq 0.0013$ for all comparisons) and melanization levels did not change from the initial to final readings of any age or treatment group (Šidák's: $P \geq 0.5840$ for all comparisons). Data were analyzed by two-way ANOVA, followed by Šidák's post-hoc test. Whiskers denote the SEM. (PDF $138 \mathrm{~kb}$ )

Additional file 6: Figure S5. Relative expression of pathogen recognition and signal transduction genes. Graphs show the average mRNA fold change of pathogen recognition (a) and signal transduction (b) genes in naïve, 
injured, and E. coli-infected larvae, 1-day-old adults, and 5-day-old adults at $24 \mathrm{~h}$ post-treatment relative to the naiive group of a given life stage or adult age. Whiskers denote the SEM. Asterisks denote the significant regulation of mRNA levels relative to the naive group as determined by the Kruskal-Wallis test, followed by Dunn's post-hoc test $\left({ }^{*} P<0.05\right.$, ${ }^{* *} P<0.01,{ }^{* * *} P<0.001$,

$* * * * P<0.0001$ ). (PDF $138 \mathrm{~kb}$ )

Additional file 7: Figure S6. Relative expression of signal modulation, immune effector, ecdysteroid biosynthesis, and ribosomal genes. Graphs show the average mRNA fold change of signal modulation (a), immune effector (b), ecdysteroid biosynthesis (c) and ribosomal (d) genes in naïve, injured, and E. coli-infected larvae, 1-day-old adults, and 5-day-old adults at $24 \mathrm{~h}$ post-treatment relative to the naive group of a given life stage or adult age. Whiskers denote the SEM. Asterisks denote the significant regulation of mRNA levels relative to the naiive group as determined by the Kruskal-Wallis test, followed by Dunn's post-hoc test $\left({ }^{*} P<0.05\right.$, ${ }^{* *} P<0.01,{ }^{* *} P<0.001,{ }^{* * * *} P<0.0001$ ). (PDF $136 \mathrm{~kb}$ )

\section{Abbreviations}

ANOVA: Analysis of variance; CFU: Colony forming unit; DETC: Sodium diethyldithiocarbamate trihydrate; DIC: Differential interference contrast; EDF: Extended depth of focus; GFP: Green fluorescent protein; LB: LuriaBertani; L-DOPA: 3,4-Dihydroxy-L-phenylalanine; OD: Optical density; ROI: Region of interest

\section{Acknowledgments}

We thank Dr. Jiannong Xu (New Mexico State University) for kindly providing Enterobacter sp. isolate Ag1. We also thank Dr. Patrick Abbot, Dr. Lisa Brown, Dr. Lillian Shapiro, Leah T. Sigle, and Bryan Joosse for helpful discussions and for feedback on the manuscript.

\section{Funding}

This work was funded by National Institutes of Health/National Institute for Allergy and Infectious Disease grant R21-Al119596 to JFH. The funders had no role in study design, data collection and analysis, decision to publish, or preparation of the manuscript. VAG-L participated through the School for Science and Math at Vanderbilt.

\section{Availability of data and materials}

The datasets supporting the conclusions of this article are included within the article and its additional files.

\section{Authors' contributions}

GPL and JFH designed the study; GPL, TYE-L, YY, and VAG-L performed the experiments; GPL, TYE, YY, VAG-L, and JFH analyzed the data; GPL and JFH wrote the manuscript. All authors read and approved the final manuscript.

\section{Ethics approval and consent to participate}

Not applicable.

\section{Consent for publication}

Not applicable.

\section{Competing interests}

The authors declare that they have no competing interests.

\section{Publisher's Note}

Springer Nature remains neutral with regard to jurisdictional claims in published maps and institutional affiliations.

\section{Received: 9 April 2017 Accepted: 20 July 2017}

\section{Published online: 01 August 2017}

\section{References}

1. Hillyer JF. Mosquito immunity. Adv Exp Med Biol. 2010;708:218-38.

2. Hillyer JF. Insect immunology and hematopoiesis. Dev Comp Immunol. 2016;58:102-18.

3. Hillyer JF, Strand MR. Mosquito hemocyte-mediated immune responses. Curr Opin Insect Sci. 2014;3:14-21.
4. Sim S, Jupatanakul N, Dimopoulos G. Mosquito immunity against arboviruses. Viruses. 2014;6:4479-504.

5. Cheng G, Liu Y, Wang P, Xiao X. Mosquito defense strategies against viral infection. Trends Parasitol. 2016:32:177-86.

6. Blair CD, Olson KE. Mosquito immune responses to arbovirus infections. Curr Opin Insect Sci. 2014:3:22-9.

7. Bartholomay LC. Infection barriers and responses in mosquito-filarial worm interactions. Curr Opin Insect Sci. 2014;3:37-42.

8. Erickson SM, Xi Z, Mayhew GF, Ramirez JL, Aliota MT, Christensen BM, et al. Mosquito infection responses to developing filarial worms. PLoS Negl Trop Dis. 2009:3:e529.

9. Clayton AM, Dong Y, Dimopoulos G. The Anopheles innate immune system in the defense against malaria infection. J Innate Immun. 2014;6:169-81.

10. Severo MS, Levashina EA. Mosquito defenses against Plasmodium parasites. Curr Opin Insect Sci. 2014:3:30-6.

11. League GP, Hillyer JF. Functional integration of the circulatory, immune, and respiratory systems in mosquito larvae: pathogen killing in the hemocyterich tracheal tufts. BMC Biol. 2016;14:78.

12. Christophides GK, Zdobnov E, Barillas-Mury C, Birney E, Blandin S, Blass C, et al. Immunity-related genes and gene families in Anopheles gambiae. Science. 2002;298:159-65.

13. Estevez-Lao TY, Hillyer JF. Involvement of the Anopheles gambiae Nimrod gene family in mosquito immune responses. Insect Biochem Mol Biol. 2014:44:12-22.

14. Gupta L, Molina-Cruz A, Kumar S, Rodrigues J, Dixit R, Zamora RE, et al. The STAT pathway mediates late-phase immunity against Plasmodium in the mosquito Anopheles gambiae. Cell Host Microbe. 2009;5:498-507.

15. Li B, Calvo E, Marinotti O, James AA, Paskewitz SM. Characterization of the c-type lysozyme gene family in Anopheles gambiae. Gene. 2005;360:131-9.

16. Müller HM, Dimopoulos G, Blass C, Kafatos FC. A hemocyte-like cell line established from the malaria vector Anopheles gambiae expresses six prophenoloxidase genes. J Biol Chem. 1999:274:11727-35.

17. Neira Oviedo M, Ribeiro JM, Heyland A, VanEkeris L, Moroz T, Linser PJ. The salivary transcriptome of Anopheles gambiae (Diptera: Culicidae) larvae: a microarray-based analysis. Insect Biochem Mol Biol. 2009;39:382-94.

18. Suwanchaichinda C, Kanost MR. The serpin gene family in Anopheles gambiae. Gene. 2009;442:47-54.

19. Ursic Bedoya RJ, Mitzey AM, Obraztsova M, Lowenberger C. Molecular cloning and transcriptional activation of lysozyme-encoding CDNAs in the mosquito Aedes aegypti. Insect Mol Biol. 2005;14:89-94.

20. Vizioli J, Bulet P, Charlet M, Lowenberger C, Blass C, Müller HM, et al. Cloning and analysis of a cecropin gene from the malaria vector mosquito, Anopheles gambiae. Insect Mol Biol. 2000;9:75-84.

21. Vizioli J, Bulet P, Hoffmann JA, Kafatos FC, Müller HM, Dimopoulos G. Gambicin: a novel immune responsive antimicrobial peptide from the malaria vector Anopheles gambiae. Proc Natl Acad Sci USA. 2001;98:12630-5.

22. Volz J, Osta MA, Kafatos FC, Müller HM. The roles of two clip domain serine proteases in innate immune responses of the malaria vector Anopheles gambiae. J Biol Chem. 2005:280:40161-8.

23. Costa-da-Silva AL, Marinotti O, Ribeiro JM, Silva MC, Lopes AR, Barros MS, et al. Transcriptome sequencing and developmental regulation of gene expression in Anopheles aquasalis. PLoS Negl Trop Dis. 2014;8:e3005.

24. Koutsos AC, Blass C, Meister S, Schmidt S, MacCallum RM, Soares MB, et al. Life cycle transcriptome of the malaria mosquito Anopheles gambiae and comparison with the fruit fly Drosophila melanogaster. Proc Natl Acad Sci USA. 2007;104:11304-9.

25. Venancio TM, Cristofoletti PT, Ferreira C, Verjovski-Almeida S, Terra WR. The Aedes aegypti larval transcriptome: a comparative perspective with emphasis on trypsins and the domain structure of peritrophins. Insect Mol Biol. 2009:18:33-44.

26. Castillo JC, Robertson AE, Strand MR. Characterization of hemocytes from the mosquitoes Anopheles gambiae and Aedes aegypti. Insect Biochem Mol Biol. 2006:36:891-903.

27. Wang Z, Lu A, Li X, Shao Q, Beerntsen BT, Liu C, et al. A systematic study on hemocyte identification and plasma prophenoloxidase from Culex pipiens quinquefasciatus at different developmental stages. Exp Parasitol. 2011;127:135-41.

28. Dimopoulos G, Richman A, Müller HM, Kafatos FC. Molecular immune responses of the mosquito Anopheles gambiae to bacteria and malaria parasites. Proc Natl Acad Sci USA. 1997:94:11508-13.

29. Meredith JM, Hurd H, Lehane MJ, Eggleston P. The malaria vector mosquito Anopheles gambiae expresses a suite of larval-specific defensin genes. Insect Mol Biol. 2008;17:103-12 
30. Richman AM, Bulet P, Hetru C, Barillas-Mury C, Hoffmann JA, Kafalos FC. Inducible immune factors of the vector mosquito Anopheles gambiae: biochemical purification of a defensin antibacterial peptide and molecular cloning of preprodefensin cDNA. Insect Mol Biol. 1996;5:203-10.

31. Shin SW, Kokoza V, Bian G, Cheon HM, Kim YJ, Raikhel AS. REL1, a homologue of Drosophila dorsal, regulates toll antifungal immune pathway in the female mosquito Aedes aegypti. J Biol Chem. 2005;280:16499-507.

32. Biron DG, Agnew P, Marché L, Renault L, Sidobre C, Michalakis Y. Proteome of Aedes aegypti larvae in response to infection by the intracellular parasite Vavraia culicis. Int J Parasitol. 2005;35:1385-97.

33. Brey PT, Lebrun RA, Papierok B, Ohayon H, Vennavalli S, Hafez J. Defense reactions by larvae of Aedes aegypti during infection by the aquatic fungus Lagenidium giganteum (Oomycete). Cell Tissue Res. 1988;253:245-50.

34. Hamilton WD. The moulding of senescence by natural selection. J Theor Biol. 1966;12:12-45.

35. Koella JC, Lynch PA, Thomas MB, Read AF. Towards evolution-proof malaria control with insecticides. Evol Appl. 2009;2:469-80.

36. Monaghan $\mathrm{P}$, Charmantier A, Nussey DH, Ricklefs RE. The evolutionary ecology of senescence. Funct Ecol. 2008;22:371-8.

37. Rono MK, Whitten MM, Oulad-Abdelghani M, Levashina EA, Marois E. The major yolk protein vitellogenin interferes with the anti-Plasmodium response in the malaria mosquito Anopheles gambiae. PLoS Biol. 2010;8:e1000434.

38. Pompon J, Levashina EA. A new role of the mosquito complement-like cascade in male fertility in Anopheles gambiae. PLoS Biol. 2015;13:e1002255.

39. Hurd H, Taylor PJ, Adams D, Underhill A, Eggleston P. Evaluating the costs of mosquito resistance to malaria parasites. Evolution. 2005;59:2560-72.

40. Moran NA. Adaptation and constraint in the complex life cycles of animals. Annu Rev Ecol Syst. 1994;25:573-600.

41. Fellous S, Lazzaro BP. Potential for evolutionary coupling and decoupling of larval and adult immune gene expression. Mol Ecol. 2011;20:1558-67.

42. League GP, Onuh OC, Hillyer JF. Comparative structural and functional analysis of the larval and adult dorsal vessel and its role in hemolymph circulation in the mosquito Anopheles gambiae. J Exp Biol. 2015;218:370-80.

43. Jiang J, Alvarez C, Kukutla P, Yu W, Xu J. Draft genome sequences of Enterobacter sp. isolate $\mathrm{Ag} 1$ from the midgut of the malaria mosquito Anopheles gambiae. J Bacteriol. 2012;194:5481.

44. Wang Y, Gilbreath TM, Kukutla P, Yan G, Xu J. Dynamic gut microbiome across life history of the malaria mosquito Anopheles gambiae in Kenya. PLoS One. 2011;6:e24767.

45. Coggins SA, Estevez-Lao TY, Hillyer JF. Increased survivorship following bacterial infection by the mosquito Aedes aegypti as compared to Anopheles gambiae correlates with increased transcriptional induction of antimicrobial peptides. Dev Comp Immunol. 2012;37:390-401.

46. King JG, Hillyer JF. Spatial and temporal in vivo analysis of circulating and sessile immune cells in mosquitoes: hemocyte mitosis following infection. BMC Biol. 2013;11:55.

47. Hillyer JF, Schmidt SL, Fuchs JF, Boyle JP, Christensen BM. Age-associated mortality in immune challenged mosquitoes (Aedes aegypti) correlates with a decrease in haemocyte numbers. Cell Microbiol. 2005;7:39-51.

48. King JG, Hillyer JF. Infection-induced interaction between the mosquito circulatory and immune systems. PLoS Pathog. 2012;8:e1003058.

49. Musselman LP, Fink JL, Narzinski K, Ramachandran PV, Hathiramani SS, Cagan RL, et al. A high-sugar diet produces obesity and insulin resistance in wild-type Drosophila. Dis Model Mech. 2011:4:842-9.

50. Moret $Y$, Schmid-Hempel P. Survival for immunity: the price of immune system activation for bumblebee workers. Science. 2000;290:1166-8.

51. Haine ER, Pollitt LC, Moret Y, Siva-Jothy MT, Rolff J. Temporal patterns in immune responses to a range of microbial insults (Tenebrio molitor). J Insect Physiol. 2008:54:1090-7.

52. Schneider CA, Rasband WS, Eliceiri KW. NIH image to ImageJ: 25 years of image analysis. Nat Methods. 2012;9:671-5.

53. Livak KJ, Schmittgen TD. Analysis of relative gene expression data using real-time quantitative PCR and the 2(-Delta Delta C(T)) method. Methods. 2001;25:402-8.

54. Strand MR. The insect cellular immune response. Insect Sci. 2008;15:1-14.

55. Sigle LT, Hillyer JF. Mosquito hemocytes preferentially aggregate and phagocytose pathogens in the periostial regions of the heart that experience the most hemolymph flow. Dev Comp Immunol. 2016;55:90-101.

56. Hillyer JF, Christensen BM. Characterization of hemocytes from the yellow fever mosquito, Aedes aegypti. Histochem Cell Biol. 2002;117:431-40.
57. Hillyer JF, Schmidt SL, Christensen BM. Rapid phagocytosis and melanization of bacteria and Plasmodium sporozoites by hemocytes of the mosquito Aedes aegypti. J Parasitol. 2003;89:62-9.

58. Yassine H, Osta MA. Anopheles gambiae innate immunity. Cell Microbiol. 2010;12:1-9.

59. Christensen BM, Li J, Chen CC, Nappi AJ. Melanization immune responses in mosquito vectors. Trends Parasitol. 2005;21:192-9.

60. Thomas P, Kenny N, Eyles D, Moreira LA, O'Neill SL, Asgari S. Infection with the wMel and wMelPop strains of Wolbachia leads to higher levels of melanization in the hemolymph of Drosophila melanogaster, Drosophila simulans and Aedes aegypti. Dev Comp Immunol. 2011;35:360-5.

61. Sidjanski S, Mathews GV, Vanderberg JP. Electrophoretic separation and identification of phenoloxidases in hemolymph and midgut of adult Anopheles stephensi mosquitoes. J Parasitol. 1997;83:686-91.

62. Zhao X, Ferdig MT, Li J, Christensen BM. Biochemical pathway of melanotic encapsulation of Brugia malayi in the mosquito, Armigeres subalbatus. Dev Comp Immunol. 1995;19:205-15.

63. Feng C, Song Q, Lü W, Lu J. Purification and characterization of hemolymph prophenoloxidase from Ostrinia furnacalis (Lepidoptera: Pyralidae) larvae. Comp Biochem Physiol B Biochem Mol Biol. 2008;151:139-46.

64. Ajamhassani M, Sendi JJ, Farsi MJ, Zibaee A. Purification and characterization of phenoloxidase from the hemolymph of Hyphantria cunea (Lepidoptera: Arctiidae). Invertebrate Surviv J. 2012;9:64-71.

65. Ryazanova AD, Alekseev AA, Slepneva IA. The phenylthiourea is a competitive inhibitor of the enzymatic oxidation of DOPA by phenoloxidase. J Enzyme Inhib Med Chem. 2012;27:78-83.

66. Pinto SB, Lombardo F, Koutsos AC, Waterhouse RM, McKay K, An C, et al. Discovery of Plasmodium modulators by genome-wide analysis of circulating hemocytes in Anopheles gambiae. Proc Natl Acad Sci USA. 2009; 106:21270-5.

67. Osta MA, Christophides GK, Kafatos FC. Effects of mosquito genes on Plasmodium development. Science. 2004;303:2030-2.

68. Schnitger AK, Yassine H, Kafatos FC, Osta MA. Two C-type lectins cooperate to defend Anopheles gambiae against gram-negative bacteria. J Biol Chem. 2009;284:17616-24.

69. Dong Y, Dimopoulos G. Anopheles fibrinogen-related proteins provide expanded pattern recognition capacity against bacteria and malaria parasites. J Biol Chem. 2009;284:9835-44.

70. Warr E, Das S, Dong Y, Dimopoulos G. The gram-negative bacteria-binding protein gene family: its role in the innate immune system of Anopheles gambiae and in anti-Plasmodium defence. Insect Mol Biol. 2008;17:39-51.

71. Levashina EA, Moita LF, Blandin S, Vriend G, Lagueux M, Kafatos FC. Conserved role of a complement-like protein in phagocytosis revealed by dsRNA knockout in cultured cells of the mosquito, Anopheles gambiae. Cell. 2001;104:709-18.

72. Moita LF, Wang-Sattler R, Michel K, Zimmermann T, Blandin S, Levashina EA, et al. In vivo identification of novel regulators and conserved pathways of phagocytosis in A. gambiae. Immunity. 2005;23:65-73.

73. Estévez-Lao TY, Hillyer JF. Involvement of the Anopheles gambiae nimrod gene family in mosquito immune responses. Insect Biochem Mol Biol. 2014:44:12-22.

74. Dimopoulos G, Christophides GK, Meister S, Schultz J, White KP, BarillasMury C, et al. Genome expression analysis of Anopheles gambiae: responses to injury, bacterial challenge, and malaria infection. Proc Natl Acad Sci USA. 2002:99:8814-9.

75. González-Lázaro M, Dinglasan RR, FeL H-H, Rodríguez MH, Laclaustra M, Jacobs-Lorena M, et al. Anopheles gambiae Croquemort SCRBQ2 expression profile in the mosquito and its potential interaction with the malaria parasite Plasmodium berghei. Insect Biochem Mol Biol. 2009;39:395-402

76. Abraham EG, Pinto SB, Ghosh A, Vanlandingham DL, Budd A, Higgs S, et al. An immune-responsive serpin, SRPN6, mediates mosquito defense against malaria parasites. Proc Natl Acad Sci USA. 2005;102:16327-32.

77. Pinto SB, Kafatos FC, Michel K. The parasite invasion marker SRPN6 reduces sporozoite numbers in salivary glands of Anopheles gambiae. Cell Microbiol. 2008;10:891-8.

78. Ramirez JL, Dimopoulos G. The toll immune signaling pathway control conserved anti-dengue defenses across diverse Ae. aegypti strains and against multiple dengue virus serotypes. Dev Comp Immunol. 2010;34:625-9.

79. Xi Z, Ramirez JL, Dimopoulos G. The Aedes aegypti toll pathway controls dengue virus infection. PLoS Pathog. 2008;4:e1000098. 
80. Garver LS, Bahia AC, Das S, Souza-Neto JA, Shiao J, Dong Y, et al. Anopheles Imd pathway factors and effectors in infection intensity-dependent antiPlasmodium action. PLoS Pathog. 2012;8:e1002737.

81. Dong Y, Morton JC, Ramirez JL, Souza-Neto JA, Dimopoulos G. The entomopathogenic fungus Beauveria bassiana activate toll and JAK-STAT pathway-controlled effector genes and anti-dengue activity in Aedes aegypti. Insect Biochem Mol Biol. 2012;42:126-32.

82. Souza-Neto JA, Sim S, Dimopoulos G. An evolutionary conserved function of the JAK-STAT pathway in anti-dengue defense. Proc Natl Acad Sci USA. 2009;106:17841-6.

83. Kim W, Koo H, Richman AM, Seeley D, Vizioli J, Klocko AD, et al. Ectopic expression of a cecropin transgene in the human malaria vector mosquito Anopheles gambiae (Diptera: Culicidae): effects on susceptibility to Plasmodium. J Med Entomol. 2004;41:447-55.

84. Blandin S, Moita LF, Köcher T, Wilm M, Kafatos FC, Levashina EA. Reverse genetics in the mosquito Anopheles gambiae: targeted disruption of the Defensin gene. EMBO Rep. 2002;3:852-6.

85. Vizioli J, Richman AM, Uttenweiler-Joseph S, Blass C, Bulet P. The defensin peptide of the malaria vector mosquito Anopheles gambiae: antimicrobial activities and expression in adult mosquitoes. Insect Biochem Mol Biol. 2001;31:241-8

86. Baton LA, Robertson A, Warr E, Strand MR, Dimopoulos G. Genome-wide transcriptomic profiling of Anopheles gambiae hemocytes reveals pathogenspecific signatures upon bacterial challenge and Plasmodium berghei infection. BMC Genomics. 2009;10:257.

87. Ahmed A, Martín D, Manetti AG, Han SJ, Lee WJ, Mathiopoulos KD, et al. Genomic structure and ecdysone regulation of the prophenoloxidase 1 gene in the malaria vector Anopheles gambiae. Proc Natl Acad Sci USA. 1999;96:14795-800.

88. Li B, Paskewitz SM. A role for lysozyme in melanization of Sephadex beads in Anopheles gambiae. J Insect Physiol. 2006;52:936-42.

89. Kajla MK, Shi L, Li B, Luckhart S, Li J, Paskewitz SM. A new role for an old antimicrobial: lysozyme c-1 can function to protect malaria parasites in Anopheles mosquitoes. PLoS One. 2011;6:e19649.

90. Kajla MK, Andreeva O, Gilbreath TM, Paskewitz SM. Characterization of expression, activity and role in antibacterial immunity of Anopheles gambiae lysozyme c-1. Comp Biochem Physiol B Biochem Mol Biol. 2010;155:201-9.

91. Hillyer JF, Estévez-Lao TY. Nitric oxide is an essential component of the hemocyte-mediated mosquito immune response against bacteria. Dev Comp Immunol. 2010;34:141-9.

92. Molina-Cruz A, DeJong RJ, Charles B, Gupta L, Kumar S, Jaramillo-Gutierrez $\mathrm{G}$, et al. Reactive oxygen species modulate Anopheles gambiae immunity against bacteria and Plasmodium. J Biol Chem. 2008;283:3217-23.

93. Kumar S, Christophides GK, Cantera R, Charles B, Han YS, Meister S, et al. The role of reactive oxygen species on Plasmodium melanotic encapsulation in Anopheles gambiae. Proc Natl Acad Sci USA. 2003;100:14139-44.

94. Kumar S, Molina-Cruz A, Gupta L, Rodrigues J, Barillas-Mury C. A peroxidase/ dual oxidase system modulates midgut epithelial immunity in Anopheles gambiae. Science. 2010;327:1644-8.

95. Oliveira JH, Gonçalves RL, Lara FA, Dias FA, Gandara AC, Menna-Barreto RF, et al. Blood meal-derived heme decreases ROS levels in the midgut of Aedes aegypti and allows proliferation of intestinal microbiota. PLoS Pathog. 2011;7:e1001320.

96. Pondeville E, Maria A, Jacques JC, Bourgouin C, Dauphin-Villemant C. Anopheles gambiae males produce and transfer the vitellogenic steroid hormone 20-hydroxyecdysone to females during mating. Proc Natl Acad Sci USA. 2008;105:19631-6.

97. Sieglaff DH, Duncan KA, Brown MR. Expression of genes encoding proteins involved in ecdysteroidogenesis in the female mosquito, Aedes aegypti. Insect Biochem Mol Biol. 2005;35:471-90.

98. Federici BA, Park HW, Bideshi DK, Wirth MC, Johnson JJ, Sakano Y, et al. Developing recombinant bacteria for control of mosquito larvae. J Am Mosq Control Assoc. 2007;23:164-75.

99. Honti V, Csordás G, Kurucz É, Márkus R, Andó I. The cell-mediated immunity of Drosophila melanogaster: hemocyte lineages, immune compartments, microanatomy and regulation. Dev Comp Immunol. 2014:42:47-56.

100. Jiang H, Vilcinskas A, Kanost MR. Immunity in lepidopteran insects. Adv Exp Med Biol. 2010;708:181-204.

101. Lemaitre B, Hoffmann J. The host defense of Drosophila melanogaster. Annu Rev Immunol. 2007;25:697-743.
102. Anderson BB, Scott A, Dukas R. Social behavior and activity are decoupled in larval and adult fruit flies. Behav Ecol. 2016;27:820-8.

103. Aguirre JD, Blows MW, Marshall DJ. The genetic covariance between life cycle stages separated by metamorphosis. Proc Biol Sci. 2014;281:20141091.

104. Quigley IK, Turner JM, Nuckels RJ, Manuel JL, Budi EH, MacDonald EL, et al. Pigment pattern evolution by differential deployment of neural crest and post-embryonic melanophore lineages in Danio fishes. Development. 2004;131:6053-69.

105. Phillips PC. Genetic constraints at the metamorphic boundary: morphological development in the wood frog, Rana sylvatica. J Evol Biol. 1998;11:453-63.

106. Parichy DM. Experimental analysis of character coupling across a complex life cycle: pigment pattern metamorphosis in the tiger salamander, Ambystoma tigrinum tigrinum. J Morphol. 1998;237:53-67.

107. Stoks R, Córdoba-Aguilar A. Evolutionary ecology of odonata: a complex life cycle perspective. Annu Rev Entomol. 2012;57:249-65.

108. Ebenman B. Evolution in organisms that change their niches during the life cycle. Am Nat. 1992;139:990-1021.

109. Rani A, Sharma A, Rajagopal R, Adak T, Bhatnagar RK. Bacterial diversity analysis of larvae and adult midgut microflora using culture-dependent and culture-independent methods in lab-reared and field-collected Anopheles stephensi - an Asian malarial vector. BMC Microbiol. 2009;9:96.

110. Cornet S, Gandon S, Rivero A. Patterns of phenoloxidase activity in insecticide resistant and susceptible mosquitoes differ between laboratoryselected and wild-caught individuals. Parasit Vectors. 2013;6:315.

111. Kirkwood TB. Evolution of ageing. Nature. 1977;270:301-4.

112. Ferdig MT, Beerntsen BT, Spray FJ, Li J, Christensen BM. Reproductive costs associated with resistance in a mosquito-filarial worm system. Am J Trop Med Hyg. 1993;49:756-62.

113. Yan G, Christensen BM, Severson DW. Comparisons of genetic variability and genome structure among mosquito strains selected for refractoriness to a malaria parasite. J Hered. 1997:88:187-94.

114. Ahmed AM, Hurd H. Immune stimulation and malaria infection impose reproductive costs in Anopheles gambiae via follicular apoptosis. Microbes Infect. 2006;8:308-15.

115. Ahmed AM, Baggott SL, Maingon $R$, Hurd $H$. The costs of mounting an immune response are reflected in the reproductive fitness of the mosquito Anopheles gambiae. Oikos. 2002;97:371-7.

116. Pigeault R, Nicot A, Gandon S, Rivero A. Mosquito age and avian malaria infection. Malar J. 2015;14:383.

117. Li J, Tracy JW, Christensen BM. Relationship of hemolymph phenol oxidase and mosquito age in Aedes aegypti. J Invertebr Pathol. 1992;60:188-91.

118. Chun J, Riehle M, Paskewitz SM. Effect of mosquito age and reproductive status on melanization of sephadex beads in Plasmodium-refractory and -susceptible strains of Anopheles gambiae. J Invertebr Pathol. 1995;66:11-7.

119. Schwartz A, Koella JC. Melanization of Plasmodium falciparum and C-25 sephadex beads by field-caught Anopheles gambiae (Diptera: Culicidae) from southern Tanzania. J Med Entomol. 2002;39:84-8.

120. Christensen BM, LaFond MM, Christensen LA. Defense reactions of mosquitoes to filarial worms: effect of host age on the immune response to Dirofilaria immitis microfilariae. J Parasitol. 1986;72:212-5.

121. Horn L, Leips J, Starz-Gaiano M. Phagocytic ability declines with age in adult Drosophila hemocytes. Aging Cell. 2014;13:719-28.

122. Mackenzie DK, Bussière LF, Tinsley MC. Senescence of the cellular immune response in Drosophila melanogaster. Exp Gerontol. 2011;46:853-9.

123. Felix TM, Hughes KA, Stone EA, Drnevich JM, Leips J. Age-specific variation in immune response in Drosophila melanogaster has a genetic basis. Genetics. 2012;191:989-1002.

124. Stoehr AM. Inter- and intra-sexual variation in immune defence in the cabbage white butterfly, Pieris rapae L. (Lepidoptera: Pieridae). Ecol Entomol. 2007;32:188-93.

125. Prasai K, Karlsson B. Variation in immune defence in relation to age in the green-veined white butterfly (Pieris napi L.). J Invertebr Pathol. 2012;111:252-4.

126. Doums $C$, Moret $Y$, Benelli $E$, Schmid-Hempel P. Senescence of immune defence in Bombus workers. Ecol Entomol. 2002;27:138-44.

127. Moret $Y$, Schmid-Hempel P. Immune responses of bumblebee workers as a function of individual and colony age: senescence versus plastic adjustment of the immune function. Oikos. 2009;118:371-8.

128. Wilson-Rich N, Dres ST, Starks PT. The ontogeny of immunity: development of innate immune strength in the honey bee (Apis mellifera). J Insect Physiol. 2008;54:1392-9. 
129. Schmid MR, Brockmann A, Pirk CW, Stanley DW, Tautz J. Adult honeybees (Apis mellifera L.) abandon hemocytic, but not phenoloxidase-based immunity. J Insect Physiol. 2008;54:439-44.

130. Laughton AM, Boots M, Siva-Jothy MT. The ontogeny of immunity in the honey bee, Apis mellifera L. following an immune challenge. J Insect Physiol. 2011:57:1023-32.

131. Eleftherianos I, Baldwin H. Ffrench-constant RH, Reynolds SE. Developmental modulation of immunity: changes within the feeding period of the fifth larval stage in the defence reactions of Manduca sexta to infection by Photorhabdus. J Insect Physiol. 2008;54:309-18.

132. Adamo SA, Jensen M, Younger M. Changes in lifetime immunocompetence in male and female Gryllus texensis (formerly G. integer): trade-offs between immunity and reproduction. Anim Behav. 2001;62:417-25.

133. Kaaya GP, Darji N. The humoral defense system in tsetse: differences in response due to age, sex and antigen types. Dev Comp Immunol. 1988;12: 255-68

134. Rolff J. Effects of age and gender on immune function of dragonflies (Odonata, Lestidae) from a wild population. Can J Zool. 2001;79:2176-80.

135. Kurtz J. Phagocytosis by invertebrate hemocytes: causes of individual variation in Panorpa vulgaris scorpionflies. Microsc Res Tech. 2002;57:456-68.

136. Travers LM, Garcia-Gonzalez F, Simmons LW. Live fast die young life history in females: evolutionary trade-off between early life mating and lifespan in female Drosophila melanogaster. Sci Rep. 2015;5:15469.

137. Bartholomay LC, Mayhew GF, Fuchs JF, Rocheleau TA, Erickson SM, Aliota MT, et al. Profiling infection responses in the haemocytes of the mosquito, Aedes aegypti. Insect Mol Biol. 2007;16:761-76.

138. Bryant WB, Michel K. Blood feeding induces hemocyte proliferation and activation in the African malaria mosquito, Anopheles gambiae Giles. J Exp Biol. 2014;217:1238-45

139. Bryant WB, Michel K. Anopheles gambiae hemocytes exhibit transient states of activation. Dev Comp Immunol. 2016;55:119-29.

140. Castillo J, Brown MR, Strand MR. Blood feeding and insulin-like peptide 3 stimulate proliferation of hemocytes in the mosquito Aedes aegypti. PLoS Pathog. 2011;7:e1002274.

141. Christensen BM, Huff BM, Miranpuri GS, Harris KL, Christensen LA. Hemocyte population changes during the immune response of Aedes aegypti to inoculated microfilariae of Dirofilaria immitis. J Parasitol. 1989;75:119-23.

142. Foley DA. Innate cellular defense by mosquito hemocytes. In: Bulla Jr LA Cheng TC, editors. Invertebrate models for biomedical research. New York: Springer US; 1978. p. 113-44.

143. Hillyer JF, Schmidt SL, Christensen BM. Hemocyte-mediated phagocytosis and melanization in the mosquito Armigeres subalbatus following immune challenge by bacteria. Cell Tissue Res. 2003;313:117-27.

144. Nazario-Toole AE, Wu LP. Phagocytosis in insect immunity. Adv Insect Physiol. 2017:52:35-82

145. Smith RC, King JG, Tao D, Zeleznik OA, Brando C, Thallinger GG, et al. Molecular profiling of phagocytic immune cells in Anopheles gambiae reveals integral roles for hemocytes in mosquito innate immunity. Mol Cell Proteomics. 2016;15:3373-87.

146. Doran CR, Estevez-Lao TY, Hillyer JF. Mosquito aging modulates the heart rate and the proportional directionality of heart contractions. J Insect Physiol. 2017;

147. Ribeiro C, Brehélin M. Insect haemocytes: what type of cell is that? J Insect Physiol. 2006;52:417-29.

148. Whitten MM, Coates CJ. Re-evaluation of insect melanogenesis research: views from the dark side. Pigment Cell Melanoma Res. 2017;30:386-401.

149. Arbouzova NI, Zeidler MP. JAK/STAT signalling in Drosophila: insights into conserved regulatory and cellular functions. Development. 2006;133:2605-16.

150. Luckhart S, Vodovotz Y, Cui L, Rosenberg R. The mosquito Anopheles stephensi limits malaria parasite development with inducible synthesis of nitric oxide. Proc Natl Acad Sci USA. 1998;95:5700-5.

151. Kim CH, Muturi EJ. Effect of larval density and Sindbis virus infection on immune responses in Aedes aegypti. J Insect Physiol. 2013;59:604-10.

152. Muturi EJ. Larval rearing temperature influences the effect of malathion on Aedes aegypti life history traits and immune responses. Chemosphere. 2013;92:1111-6.

153. Muturi EJ, Kim CH, Alto BW, Berenbaum MR, Schuler MA. Larval environmental stress alters Aedes aegypti competence for Sindbis virus. Tropical Med Int Health. 2011;16:955-64.

154. Telang A, Qayum AA, Parker A, Sacchetta BR, Byrnes GR. Larval nutritional stress affects vector immune traits in adult yellow fever mosquito Aedes aegypti (Stegomyia aegypti). Med Vet Entomol. 2012;26:271-81.
155. Yadav P, Barde PV, Gokhale MD, Vipat V, Mishra AC, Pal JK, et al. Effect of temperature and insecticide stresses on Aedes aegypti larvae and their influence on the susceptibility of mosquitoes to dengue- 2 virus. Southeast Asian J Trop Med Public Health. 2005:36:1139-44.

156. Mourya DT, Yadav P, Mishra AC. Effect of temperature stress on immature stages and susceptibility of Aedes aegypti mosquitoes to chikungunya virus. Am J Trop Med Hyg. 2004;70:346-50.

157. Moller-Jacobs LL, Murdock CC, Thomas MB. Capacity of mosquitoes to transmit malaria depends on larval environment. Parasit Vectors. 2014;7:593.

158. Alto BW. Interspecific larval competition between invasive Aedes japonicus and native Aedes triseriatus (Diptera: Culicidae) and adult longevity. J Med Entomol. 2011;48:232-42.

159. Murdock CC, Paaijmans KP, Bell AS, King JG, Hillyer JF, Read AF, et al. Complex effects of temperature on mosquito immune function. Proc Biol Sci. 2012:279:3357-66.

160. Bukhari T, Takken W, Koenraadt CJ. Development of Metarhizium anisopliae and Beauveria bassiana formulations for control of malaria mosquito larvae. Parasit Vectors. 2011;4:23.

161. Capone A, Ricci I, Damiani C, Mosca M, Rossi P, Scuppa P, et al. Interactions between Asaia, Plasmodium and Anopheles: new insights into mosquito symbiosis and implications in malaria symbiotic control. Parasit Vectors. 2013;6:182.

162. Federici BA, Park HW, Bideshi DK, Wirth MC, Johnson JJ. Recombinant bacteria for mosquito control. J Exp Biol. 2003;206:3877-85.

163. Kala MK, Gunasekaran K. Effect of Bacillus thuringiensis ssp. israelensis on the development of Plasmodium gallinaceum in Aedes aegypti (Diptera: Culicidae). Ann Trop Med Parasitol. 1999;93:89-95.

164. Mahapatra N, Hazra RK, Rup S, Acharya AS, Dash AP. Bacillus sphaericus interferes with the development of Brugia malayi in Aedes aegypti. J Helminthol. 1999;73:279-80.

165. Otieno-Ayayo ZN, Zaritsky A, Wirth MC, Manasherob R, Khasdan V, Cahan R, et al. Variations in the mosquito larvicidal activities of toxins from Bacillus thuringiensis ssp. israelensis. Environ Microbiol. 2008;10:2191-9.

166. Paily KP, Geetha I, Kumar BA, Balaraman K. Bacillus sphaericus in the adults of Culex quinquefasciatus mosquitoes emerged from treated larvae and its effect on development of the filarial parasite, Wuchereria bancrofti. Parasitol Res. 2012;110:2229-35.

167. Tusting LS, Thwing J, Sinclair D, Fillinger U, Gimnig J, Bonner KE, et al. Mosquito larval source management for controlling malaria. Cochrane Database Syst Rev. 2013;8:CD008923.

168. Fillinger $U$, Lindsay SW. Larval source management for malaria control in Africa: myths and reality. Malar J. 2011;10:353.

169. Floore TG. Mosquito larval control practices: past and present. J Am Mosq Control Assoc. 2006:22:527-33.

\section{Submit your next manuscript to BioMed Central and we will help you at every step:}

- We accept pre-submission inquiries

- Our selector tool helps you to find the most relevant journal

- We provide round the clock customer support

- Convenient online submission

- Thorough peer review

- Inclusion in PubMed and all major indexing services

- Maximum visibility for your research

Submit your manuscript at www.biomedcentral.com/submit
) Biomed Central 